\title{
Seven
}

\section{NON-NATURALISTIC COGNITIVISTS}

\begin{abstract}
He must be able to give a rational explanation of all that admits of rational explanation. Plato'
\end{abstract}

\section{Non-Naturalist Empiricists}

Non-naturalist empiricists recognize value in experience sui generis that is either ontological or phenomenological. In the first case value appears as an aspect of Being, in the second as a realm of its own. In the first case, value is identified with something that is valuable; hence ontologists share with empirical naturalists the commission of the Moorean fallacy. Due to the ideal rather than sensory nature of the valuable object, they are closer to a formal view than are the naturalists. Phenomenologists are even closer to this view, the valuable object for them being value itself. From a formal point of view, while naturalistic empiricists reify what ought to be an abstraction, indeed a construction, non-naturalist empiricists hypostatize what ought to be an everyday procedure.

\section{A. Ontologists}

Here belongs the scholastic school of value. In the period under discussion, Jacques Leclercq $^{2}$ offers an exposition of the axiological view of this school-of value in general, the notions of the good and the bad, the objectivity of value, and the relationship of the good, the true, and the beautiful (in the notion of the transcendentals). In its clarity and logical structure, their account makes clear the striking resemblance to, as well as the difference between, the scholastic and the modern method of approaching the notion of values through a linguistic analysis of ordinary language. Scholastics, like moderns, find the fundamental aspect of morality in the value judgment, but instead of inventing a new "logic" of contextual "meanings," they use the method found in Socrates, Plato, and Aristotle and taken up by the authors of the middle ages, in particular, St. Thomas. It consists in examining the customary meaning in everyday value judgments and, once it is found, in rising to the concepts to which these meanings correspond and the idea of reality that it implies. Thus,

in starting with words that are on everybody's lips and from notions that seem elementary, they arrive, by a work of purification and elimination, at properly philosophical notions and at precisions that at first glance seem a little strange in relation to common conceptions even though they contain them within themselves. ${ }^{3}$ 
The usual scientific and empirical procedure is used to move from the particular to the universal. The chaos and contradictions of ordinary words and phrases are overcome by reaching, as in any scientific experiment, the fundamental and essential, discarding the inessential, ${ }^{4}$ and finally reaching, as in a scientific precipitation, the inner core of all the material and formulating it in a definition.

In the dialogues of Plato, Socrates goads his interlocutors with questions that oblige them to find what they implicitly think and to coordinate their ideas. St. Thomas, starting from the same tradition, instead of using this meandering method of Socrates goes in more direct ways. He begins with a verbal definition but elevates himself immediately to the implicit philosophical notion. The procedure is the same as the traditional, but it presents the advantage of starting with notions that everybody has the intelligence to understand and that have a familiar ring.

This method has been lost in value theory today. Either, as in the Oxford School, theorists remain in fragmentary "meanings" without desiring overall analysis, or they state universal notions without anchoring them in everyday usage. Only the phenomenological school, according to Leclercq, follows the old tradition. ${ }^{6}$ In view of its logical clarity and truly scientific procedure, at least up to analytic definition, though not all the way to the synthetic, seeing where this method leads is particularly important. It leads to a value ontology that may be expressed in many forms besides its own metaphysical terms.

Ontologically speaking, the thing is good if it is what it is, and to the degree that it is what it is. The metaphysical expression for this is "perfection." The thing is good to the degree of its perfection. Each thing has its own order of perfection. The good of a horse is not the same as that of bread, and the good of a race horse is not the same as that of a work horse. The value judgment depends on the nature of the thing judged. "If the end of a horse is to run, a perfect horse is the one which runs as well as his nature of horse-ness allows." The word "nature" designates here the set of characters that determine a thing in itself - the necessary characters of the thing, its essence. This metaphysical terminology can be expressed in many different ways. In terms of modern axiological philosophy it means that the thing is good if it has its good-making properties. Teleologically, it means the thing is good if it fulfills its purpose. Epistemologically, it means it is good if it has its essential properties. Logically, and in terms of formal axiology, it means it is good if it fulfills the intension of its concept. Bernard J. Lonergan and I have both commented elsewhere on the transition from "nature" to intension and hence to formal relations. ${ }^{8}$

Surveying the history of axiology, we have here the axiologia perennis, varying aspects of one and the same relation, the fundamental relation of axiology between the factual and the value properties of a thing. Unfortunately, the interconnection of these various meanings has never been stated, partly because they have never been clearly distinguished, partly because when distinguished they have not been synthe- 
sized. The analogy in modern axiology between good-making properties and Moore's "description," and the logical nature of "description," has not been taken seriously. From this analogy to the identity of the two and their logical natures is only one, and a fairly obvious, step. In the account of Leclercq, although the metaphysical sense is clear, the other senses-teleological, epistemological, and so on-are mixed into it. Especially, and this is the shortcoming of Aquinas's axiology, the relations between desire and perfection, and between the perfection of the individual thing and of creation as a whole, are not logically clear. The Aristotelian basis with its naturalistic fallacy spoils the logical clarity of the scholastic idea of perfection, as stated in all its purity by Saint Anselm. ${ }^{9}$

The notion of specific perfection is generalized into the perfection of an absolute being that lacks nothing and has the abundance of all properties. A perfect horse and a perfect man are absolutely good in their order. They are particular values but not the absolute value of the totality of all Being. The properties of this absolute being are the transcendentals and follow logically from its nature. They define the universal order of all being. This leads logically to the notion of bad. If each being is good to the degree that it is what it is, then bad is not found in any being taken in itself. A stone taken by itself is good in that it is what it is in realizing its type. Only an object that is not in its place either in the total or in some specific order and that does not fulfill its function or render the services that belong to it can be bad. Badness thus is an implication of the notion of order. It is disorder: it consists in the non-realization of an order. Traditionally, this was expressed as negation or deprivation of being, but Leclercq believes a more fortunate formula for bad defines it as disorder. This throws an interesting light on Oxford philosophy, which disdains order. The notion of "bad" appears in formal axiology as logical disorder (transposition of frames of reference). ${ }^{10}$

Ontological axiology is so articulate because, at bottom, it is only a hypostatization of logical relations. As Hermann Lotze indicated, logical relations lead to axiological ones." These logical relations may be recovered by a dehypostatization of ontological axiology. As it is, ontological axiology, in its most developed form, is to formal or logical axiology as a mirrored image is to its origin.

Variations of the ontological view of value are found in all countries of the European continent and in Asia. In France, during the second post-Moorean period, we have the last works of Louis Lavelle and René Le Senne, both thinkers who regard values as guaranteed by a transcendent source, the Absolute Self, in which finite selves participate. Since Moore was practically without influence on the European continent and in other areas of non-naturalist axiology, and these theories were developed practically without reference to Moore or knowledge of his fallacy -in what we may call an axiologically naïve manner-the expression "second post-Moorean era" is here to be taken in its merely chronological sense, as covering the years of mid-twentieth-century.

For Louis Lavelle, ${ }^{12}$ modern value theory, rather than breaking with classical metaphysics, should be its heir and resurrection. Value, rather than being unreal as 
the positivists hold, not only has reality but transcends the reality of the world and gives it legitimacy. Value is "unreal" only in the sense of being the meaning of the real. It is the domain of Difference, constituted by any break of indifference-a thought found also in naturalistic French axiology (like that of Maxime Glansdorff), formalistic axiology (like that of Daniel Christoff), and particularly celebrated in the philosophy of Jean-Paul Sartre with its apotheosis of "the gap" and "the hole." It is, it seems, the axiological contribution of the French, though it finds its prototype in the negative existentialism of Martin Heidegger.

Value, for Lavelle, is the negative of indifference; it finds its ontological foundation in an Order that may well have a logic of feeling paralleling the intellectual logic of Being. Being and Value are one and the same. Where value separates itself from being, nothing remains of being but the phenomenal; it is Being stripped of its meaning - and, in so far, not truly Being. ${ }^{13}$ The unity of Being and Value is not merely abstract but, as Being particularizes itself in the participation of individual selves, so does Value. Thus arises the diversity of values that is the subject of the second posthumous volume of Lavelle's imposing work. Through it he joins from the side of ontology, and as the most profound and most comprehensive thinker, the ranks of those who give practical relevance to value theory, such as A. L. Hilliard, F. S. C. Northrop, and F. E. Sparshott.

René Le Senne's last work ${ }^{14}$ gives the final form of his sociological thought. All persons are destined to seek their value. In doing so they transcend particularity and fulfill the purpose not only of themselves but of all existence, uniting human strivings in the one Absolute Value beyond empirical or subjective determinations. Thus, persons are not only saved of the idolatries of specific hypostatizations of empirical features of nature, state, or individual, but this absolute reference makes them, as value, transparent to the highest Value, makes them live absoluteness, and existentially unites them with God. Le Senne connects the concrete study of human beings with the metaphysics of value. Value is impossible without unique persons: persons give objects their value. In this sense, value is that which enriches and is derived by the self.

The value of objects must not be confused with the object valued. We cannot localize value in objects. Value is different from objects perceived; it is rather what we seek in objects. An object is nothing but what it is, but the value in it is always bi-polar, positive or negative. A wall can have value as a protection or as a barrier, a jewel as a gift or as a bribe. Value has no confines, no limits; it is "atmospheric," suffusing everything. ${ }^{15}$ Persons as values are part of its oneness. Value is "the interexistential relation" that unites and ennobles persons.

Transcendent as this sounds, this position can be translated into logical formality. The logical counterpart to this ontological description of value is the understanding that Value is a variable rather that an instance, the solution of Moore's paradox of the "two different propositions that are both true of Goodness." For if Value is a logical variable, such as Number, it obviously cannot be localized, transcends particularity, is beyond empirical and subjective determinations, has no confines or 
limits, and "suffuses" everything by being applicable to everything. The ontological position can be derived from a consistent and imaginative application of formal axiology. But it cannot and must not take the place of such an axiology. A perceptive and lucid exposition of Le Senne's thought is given by Jules Pirlot. ${ }^{16}$ Raymond Ruyer developed a position in general similar to Lavelle's and Le Senne's in the direction of suggestive and precise models like the optic of colors ${ }^{17}$ and the teleological analysis of situational process. ${ }^{18}$ Raymond Polin followed up his work on the creation of values ${ }^{19}$ with a book on the negative aspects of the theme. ${ }^{20}$ These thinkers use their analyses as criteria to classify a wide range of value philosophies.

While French ontologists emphasis the transcendence over the immanence of value, the situation in Italy under the influence of Benedetto Croce and Giovanni Gentile is just the reverse. It emphasizes the immanence over the transcendence of value, ranging all the way from an immanence anchored in the dialectic of the spirit to one based in the existentially and even naturalistically conceived structure of the concrete human situation. Croce affirms that the category of "vitality is a necessary integration of the various forms of the spirit which would lack voice, organs, and power if...they were separated from it." ${ }^{\prime 21}$

For Giovanni Gentile, ${ }^{22}$ who structures the spiritual act in a more deontological manner, the reference of this act to being is not a transcendent but an immanent one: it is to the very activity of subjects themselves in their dialectic structure. Valuation is a matter of individual self-consciousness, born of and coinciding with the spiritual will. The philosophy of "integral immanence" of these two masters and its inherent axiological difficulties was explored by a rising school of revisionists who develop and deepen some of the idealistic themes, often in new, independent, and unexpected directions. ${ }^{23}$ But the rational character of idealist axiology and Crocean values has almost entirely been preserved. ${ }^{24}$ Where given up, as in Ugo Spirito, it has been coupled with the deepest sensibility for moral problems and replaced by a substitute perhaps even better suited for understanding the moral life.

Ugo Spirito ${ }^{25}$ manifests a counter-reaction of thoroughgoing anti- (or supra-?) intellectualism with phenomenological overtones and with a profoundly moral vindication. The metaphysical premises of Western philosophy, and of Christian philosophy in particular, led to the dogmatism of objective judgments. Those who judge oppose the thing judged to themselves, thus removing it from themselves and from true insight. Gentile's theoretical interpretation of the Act must be replaced by a creative activity of the spirit, and the objective gegenständliche relation by a new type that overcomes duality and is based in the love and solidarity between people and things. The same problematic is ethically in Martin Buber ${ }^{26}$ in his distinction between the I-It and the I-Thou relation, and logically in Edmund Husserl. The suspension of judgment cancels the particularization of individuals, brings back to each aspect of reality its original value, and precludes the formation of an abstract hierarchy of perfections (see Le Senne).

In Guido Calogero ${ }^{27}$ the anti-idealistic reaction led to a personal form of empiricism that revindicates the normative function of the dialogue. Values can be 
communicated and comprehended if only the horizon remains open and any definite solution is avoided - as long as we do not make of the logos, the transcendental principle of the dialogos, a metaphysical hypostatization. This development may lead to a profound deepening of the bases of the British "good reasons" school.

Another development leads toward a form of existentialism with overtones of Le Senne. For Armando Carlini ${ }^{28}$ the metaphysical quest arises directly out of the human situation; people are thrown into the external world, yet they cannot base the ultimate reasons of their existence upon it. The contradiction between external necessity and rational exigency can only be overcome by affirming a pure and absolute spirituality that overcomes the conflict. Thus, the value of the individual person unites with Absolute Value, which is God in the Christian sense. Contrary to the phenomenological direction of Max Scheler, who sees in God the idea of Value, Carlini identifies God with value; God is the very existence of value.

Augusto Guzzo ${ }^{29}$ too, considers human experience in the sight of the infinite, that is, of God, and bases value experience on the inevitable human aspiration to reach the divine harmony. But its inherent features - the Good, the True, the Beautiful-are not, for him Platonic prototypes in which human acts imitatively participate. They are reflections or generalizations of concrete and precisely differentiated acts of valuation - aesthetic, cognitive, and so on. The ideality and eternity of values, arising from the exigencies upon us by the Primary Value, are expressions of attributes possessed by concrete acts and must never be metaphysical hypostatizations.

Felice Battaglia ${ }^{30}$ also finds a transcendent validation for value. The idealistic thesis, in spite of distinctions made within its dialectic, resulted in such a perfect interrelationship of opposing elements, the rational and the real, the true and the factual, that it almost erased all distinctions and diffused the nature of value. To recapture it, the spiritual act, if it is not to degenerate into factuality, must be put into contact with a Principle that transcends it and gives validation, that is, meaning and consistency, to its historical manifestations. "Value is, in its origin, beyond history, even though historical reality assumes the function to assure its unification and to guarantee its coherence." In this spirit Battaglia investigates specific values of human activities-labor, judicial activity, art—and thus contributes to the human relevance of value theory in the sense of Langmead Casserley. So does, on a different basis, Michele F. Sciacca, ${ }^{31}$ who examines contemporary civilization and its chaotic character on the basis of humanity's lost metaphysical reference. Only a new and profound relationship to God can save us. In a similar direction is the philosophy of Guiseppe Capograssi ${ }^{32}$ love in the sense of the Gospel must overcome the chaos of our age.

Non-religious phenomenologico-existential analyses of value are given by Guido Lazzarini, Carlo Antoni, Nicola Abbagnano, and Guido Lazzarini, ${ }^{33}$ among others. Influenced by Søren Kierkegaard and Edmund Husserl, they see the definition of value in the subject's openness toward the manifold goals that the intentionality of the spiritual act implies. Anton ${ }^{34}$ locates the dialectic struggle entirely within 
individuals: the life of individuals is a Kierkegaardian struggle within their moral conscience between the exigencies of their individuality and those of the universal. Abbagnano, ${ }^{35}$ in contrast to the negativism of German and the spiritualism of French existentialism, introduces the category of possibility as the norm of experience and ethical law. Possibility indicates the unstable and precarious structure of experience and its problematic character. Against the romantic myth of necessity and security, Abbagnano insists that "welfare, security, peace, happiness and all we call 'values' which give a meaning and flavor to life- beauty, goodness, truth-are always insecure and mutable." Our endeavor to conserve and augment them does not guarantee success.

This position is far from the idealistic conceptions of Croce and Gentile. With only one more step, we land in the sociological contextualism of the American School. Luigi Bagolini, ${ }^{36}$ whose theory is a kind of objectified emotivism, is a transition to it. In an original and ingenious way he uses myth as a category of emotion and a definition of value. Value is a finality fundamental to consciousness and hence is not susceptible of serving as means for further finality. Cognition and will are conditioned by a variety of values that are the spontaneous projections of consciousness and can be considered as myths in the sense of profound emotional manifestations of human life. The reality of myth-value is irreducible to rationality; it is rather an objectification of the emotional, a kind of objectified Stevensonian "attitude" or Jungian archetype. Its origin is not individual but collective and involuntary. Philosophy has the task of elaborating methods with which to interpret the nature of value and resolve the conflicts of various myths. The principal interpretative instrument is sympathy: it constitutes the imaginative openness necessary for interpreters to put themselves into a situation in which myths are apt to exercise an influence on conduct. To discover the intrinsic objective meaning of myth-value, we have to reach an interpretative purity; that is, we must be sympathetic with it through the psychological processes first formulated by David Hume and Adam Smith, then deepened by Bagolini, with allusions to C. G. Jung and Husserl.

From here the way leads to a completely naturalistic direction of existential thought, as in Enzio Paci, ${ }^{37}$ who uses the principle of irreversibility -in analogy to the Second Law of Thermodynamics - as a model to interpret the meaning of the historic-natural process. Moving toward the neo-positivist school and its logico-linguistic techniques are investigations such as Ludovico Geymonat's, ${ }^{38}$ who eliminates from the concept of rationality all reference to axiomatic self-evident truths and replaces contemplation of absolute truth with the effective methodological operation of people in their actual situations.

Similar reconstructions of reason are in the rigorously immanentist conceptions of value of Franco Lombardi, Remo Cantoni, and Emilio Oggioni. Lombardi, ${ }^{39}$ after a full analysis of modern civilization, comes to the conclusion that we must reform the concept of thought itself and understand its essential capacity of self-criticism, which coincides with liberty itself and precedes all logical thought. To this reform corresponds on the moral plane the "dignity of life," regarded as the concrete reality 
of freedom, which Lombardi substitutes for the categorical imperative, regarded a merely abstract idea. Cantoni ${ }^{40}$ founds the normativity of value in the plenitude of the human situation and not in an abstract metaphysical dimension. Oggioni ${ }^{41}$ projects a radical transformation of the concept of truth in the direction of a programmatic pragmatic ideology that makes values sociologically normative.

From the bewildering and bewitching variety of Italian axiological thought, a definite direction emerges toward dehypostatization of value, toward situationally effective axiological inquiry, if not an axiological method. The direction, though implicit rather than explicit, is toward a science of value; but the corresponding critical and methodological examination of value form rather than value matter-in the spirit of G. E. Moore-is still missing. The profound insights into and ingenious approaches to value reality offered by Italian axiologists will give to formal axiology, once it is established, a manifold of dimensions and a multitude of themes by which it will have to prove itself. What is now an aggregate of unconnected analytic abstractions will become an ordered segment of a new science, a profoundly significant set of practical applications of this science to its subject matter, value.

As mentioned, the ontological view is prevalent on the European continent, in Latin-America, and in Asia. It is a rich treasure house for axiological material. In Spain and Latin America is the tradition of José Ortega y Gasset, the importance of whose little essay, What Are Values? $?^{42}$ is out of all proportion to its size. His notions of "vital reason" and "authenticity" — central themes of axiology— have found lucid expositors.

Julian Marias ${ }^{43}$ explains the concept of vital reason. Life itself is the system that is structured in and functions as human reason; the self is the essential organ of comprehension. Experience - in the existential, not the epistemological sense-is the matrix of conceptualization. Fundamentally, comprehension and valuation are the same. The differentiation of experience in conceptualization is at the same time the differentiation of valuation.

The tie between existential insight and valuation was expanded into the texture of an existential axiology by José Romano Muñoz $z^{44}$ in vigorous opposition against the value nihilism of Martin Heidegger and Jean-Paul Sartre. Metaphysics, for Romano Muñoz, converts itself into ethics; the universal reference of philosophy is not an abstract but a concrete one, based on the existential relation between the human self and the universe: "Our being is a being able to which strives to be more, a will, an aspiration to be all it can be in the full realization of its immanent possibility." This inherent dynamic of the existential self necessitates the conversion of metaphysics into ethics and merges with the axiologia perennis of perfection. "If being is essentially being-able-to, then being, as such, is being-to-perfection, ontological aspiration, whose ideal content is perfection itself, plenitude, the full integration of being."

This culmination of ontology in axiology is complemented and deepened by Luis Recaséns Siches' ${ }^{45}$ deepening of axiology into ontology ${ }^{46}$ The phenomenologico-axiological view (discussed in the next section) illegitimately splits the axiological 
from the ontological realm. On a deeper level, fact and value are reciprocally related. Although the real and the valuable are different categories and formally independent, yet one seems to exist for the other. Axiology must look for the link between the two realms. Value is not merely as primary a category as Being; it is even more basic. The mind, in building up a world, functions relatively, determined by preference judgments ruling both attention and perspective. The co-presence of the subject with its object, the I with its world, is the primary and basic reality. Consciousness, acting as a selective net, is conditioned by value attitudes. Here, then, axiology is deepened beyond ontology, with a result in naturalistic form like that of William $\mathrm{H}$. Werkmeister. But while Werkmeister interprets valuation psychologistically, Recaséns Siches rejects such interpretations. Values are not projections of psychological mechanisms or reactions, but objectively valid meanings within the context of human life. People do not create values. They are part of the texture of life, there for us to recognize. The structure of human life is conditioned by values. If the capability of judging (of values) were suppressed, human life as such would disappear. A person who could not choose could not think. He or she would be in pure suspension, in absolute abstention. Thus, a fundamental tie exists between valuation and human existence. The network of contexts and situations, which naturalists see on one flat plane, is for Recaséns Siches a multi-dimensional axio-onto-logical manifold. It is phenomenological in a sense in which, for example, Maurice Mandelbaum's axiology is not.

The ontological axiology of the Latin thinkers of Europe is for the future of axiological science a profound source of material. German ontology is even more so, but in a kind of perverted sense that fittingly corresponds to recent events of German history. In Latin Europe the hypostatization of valuations into Values proceeds in a rational fashion and with results that will have to be confirmed by formal axiology; what this value ontology calls value must correspond to formal value, and what it calls disvalue must correspond to formal disvalue. By contrast, the ontological discussion in Germany under the influence of Martin Heidegger went in an irrational if not nonsensical direction, with results that formal axiology will have to disprove-in the sense of calling value what this ontology calls disvalue.

The battle between humankind and Hitlerian nihilism was by Martin Heidegger philosophically transposed into a battle between ontology and axiology, or between Being and Value, with Hitler on the side of Value - and hence of Non-value, for Value - not being Being — was not really value; Being seen as Value lost its being as Being, and hence as Value. This argument goes the naturalistic fallacy one better by identifying Value with Non-Being and Being with Non-Value, yet supremely valuing Being. It is as if a hedonist would identity pleasure with value - thus committing the naturalistic fallacy - and then continue: If pleasure is identified with value, pleasure ceases being pleasure and becomes value. To speak of value then is hedonic nihilism and the devaluation of pleasure.

That this is nonsense is obvious. It means that $A$ is both $A$ and not- $A$. If pleasure is value then value is pleasure. If $A=B$ then $B=A$. It is nonsense to say 
that if $A=B$, then $A \neq A$, hence $A \neq B$. Yet, such is Heidegger's argument. Instead of treating it as a Lewis Carrollian joke, Germans took it so seriously that the axiological discussion in the second post-Moorean period revolved around Heideggerian value nihilism, and the word "value" actually fell into disrepute. Heidegger's claims that "Nobody dies for mere values," "Thinking in values is pure nihilism," "Thinking in values is radical killing," and similar Heideggerian statements made a deep impression on the German generation returning from Hitler's battlefields.

Martin Heidegger ${ }^{47}$ saw in axiology nothing but an Ersatz for the lost metaphysics of being. Since Immanuel Kant and the neo-Kantians banished Being to the noumenal, and in the process of cognition called into being phenomena that were not Being, a substitute for Being had to be produced, which was Value. Thus, "Value is the objectification of the desirous aims of the cognizing settling down in the world as image." ("Wert ist die Vergegenständlichung der Bedürfnisziele des vorstellenden Sich-einrichtens in der Welt als Bild.") Heidegger suggested, in a characteristic argumentum ad hominem, that value philosophers deal with value only in order to impress on others that they deal with the most valuable - whereas the most valuable is not value but being - which is Heidegger's bailiwick.

Heidegger's value philosophy, going back to Sein und Zeit, is epitomized in his analysis of Friedrich Nietzsche's words, "God is dead." ${ }^{\text {"48 }}$ Here value is definitely and explicitly identified with non-being and hence non-value - with nihilism. Nihilism, according to Heidegger, is the life-blood —or rather death-blood—of modern metaphysics; it is the fundamental movement (die Grundbewegung) of Western history; it is the devaluation of the highest values by valuing. After the "death of God" a new principle is needed, which Friedrich Nietzsche posits in The Will to Power. Value thus becomes a standard for the will to power, which now expresses the reality of the real. As a new nihilism, it had to overcome the old nihilism of historical "metaphysics" and, in doing so, to become something positive. But, insofar as it thinks value rather than being, it suffers from the same disease as that which it is to replace, and its positivity again relapses into negativity. For, value can never take the place of being. Value and being being distinct, valuing obstructs the being of being if it tries to overcome it and take its place. The separation of nihilism becomes the very culmination of nihilism; "If value will not let Being be being Being, which as Being itself it is, then the supposed overcoming is first of all the completion of nihilism." "Wenn jedoch der Wert das Sein nicht das Sein sein laesst, was es als das Sein selbst ist, dann ist die vermeintlich überwindung allererst die Vollendung des Nihilismus." $)^{49}$ The greatest blow against true value then is valuing; and the ultimate blow against God is valuing him. God "is being devalued to become the highest value" ("zum höchsten Wert herabgewürdigt"). ${ }^{50}$ To value God, the being of being, as the value of values is the "supreme blasphemy." Like all false prophets, those who strike down God this way disguise themselves as His high priests. "The non-thinking of Being disguises itself in the appearance of representing Being in the most worthy fashion." 51

Heidegger gives both immoral and illogical twists to what G. E. Moore calls the naturalistic fallacy, in its aspect of confusing being and value. For Heidegger, to 
commit this fallacy is a betrayal of being. The fallacy consists not in diluting the value nature of Value by making it dependent on being, but on diluting the being nature of Being by making it dependent on value. Being, in other words, is more valuable than value; or rather, being is more than value is valuable. Instead of the being of value being more fundamental than the value of being, the value of being is more fundamental than the being of value; or rather, instead of the value of value being more valuable than the being of being, being being the being of being is more being than the value of value is value.

Unfortunately for Heidegger's argument, this is a question of value and not of being, the question namely of what is the more fundamental philosophical truth, that of being or that of value. A question of comparison of two things by a standard- be it truth or whatever, be it with respect to being, truth, or coathangers-is always a question of value. Whenever there is a competition between thinking in terms of value and thinking in any other terms, whether being or what have you, value thinking must necessarily take the prize because competition is itself valuing.

Heidegger is right, in a Lewis Carrollian sense, in saying that "thinking in value shuts off being, from the very beginning, from essentializing in its truth." ("Das Denken nach Werten laesst im vorhinein das Sein selbst nicht dahin gelangen in seiner Wahrheit zu wesen.") ${ }^{52}$ Logically, nothing can be done about this, just as nothing can be done about +1 not being -1 . This logical truth can be obscured by sophisms, but they cannot make it false, for they contain contradictions against the very procedure they employ. To prove that $+1=-1$, let $x^{2}-1=0$. Since $x^{2}-1=(x+$ 1) $(x-1)$, if we divide $x^{2}-1=0$ by $x+1$ we get $x-1=0$, or $x=+1$; and if we divide it by $x-1$ we get $x+1=0$, or $x=-1$. The fallacy is the same as a favorite one of Heidegger, not defining the nature of Zero, or Nothing. Thus, Heidegger's axiology, or rather his anti-axiology or ontology, is a sophism. It is pseudo-thinking, for it contradicts its own procedure. It is actually a joke on philosophy, comparable only to the later Wittgenstein's. Both are anti-Socratic, and both confuse thinking with word games. The words Wittgenstein plays with are those of common sense, and the words that Heidegger plays with are those of uncommon nonsense. Both see, to speak with Heidegger, in "the reason celebrated for centuries the most obstinate adversary of thinking" ("die seit Jahrhunderten verherrlichte Vernunft die hartnäckigste Widersacherin des Denkens"), ${ }^{53}$ and both believe themselves to be radical renovators, revolutionaries of a new way of philosophizing. Both are mistaken, for both commit logical fallacies. (In the case of Wittgenstein, the fallacies were not committed by him but by his followers.)

The question comes down to asking whether fallacies make any difference in philosophical thought. If we say they do not, philosophy is reduced to a joke, if not a hoax; specious and genuine dialectic must be distinguished. ${ }^{54}$ If moral philosophy today is in the alchemistic stage, Heidegger's and to a lesser degree the Wittgensteinians' antics in this field may be compared to those of the great alchemistic prestidigitators who awed crowds and courts with their magic arts-Seyler, Hofmann, Richthausen, Sir Digby Kenelm, Nicolas Flamel, and others-who had found the 
philosopher's stone and with its help ("Take as much of it as a bean, throw it upon a thousand ounces of mercury...") performed miraculous transformations into gold, some of their works still being preserved in special coins of pure gold. Only dilettantes in the art, such as Honauer, were hanged-usually on elaborate gallows fashioned from their own products.

If we say fallacies do make a difference, then truth is still found only by rational thinking. Neither its trivialization in common sense nor its ornation in uncommon nonsense can provide the solution of problems at once so profound and so straightforward as that of value. As Moore saw long ago, and Plato long before him, the relation of being and value finds its solution in extending the naturalistic fallacy to ontology. Kierkegaard elaborated this in his doctrine of subjective truth-finding the essential truth of being in value, which means finding the essential truth of value in being as essentially value. For essentiality is itself a value term, and it is so whether the essentiality is one of being, of value, or what have you.

The phenomenological method is a method of valuation, and the establishment of special phenomenological axiologies is a redundancy. Phenomenology is itself axiology: when a thing's essence is discerned, the thing is intrinsically valued. The confusion between being and value is already found in Heidegger's master, Edmund Husserl. ${ }^{55}$ The essentiality of being is value; it is the essential value of being; and so is the essentiality of value itself, the essentiality of a butterfly and that of a coathanger. Essential being, in other words, is a value, and essential value a being, only in so far as essential being is a value. Value is the genus and being the species. Ontology, thus, is a species of axiology, not axiology a species of ontology. It is not a "substitute" for ontology, and it did not come into being after Kant. It superseded ontology from the very beginnings of philosophy in Socrates and Plato, for the simple reason that without it ontology cannot become rational. That axiology has never fulfilled its promise to ontology is another matter. Its full problematic only came into being with Kant and it culminated in Moore. It might be resolved by my interpretation of Moore's paradox - "The two different propositions both true of goodness"- as the axiom of formal axiology.

Ontology cannot "unmask" axiology, except, perhaps, one equally as vague and arbitrary as itself. Ontology, if it is to be a genuine rational discipline, must use value categories. If it does not use them, or using them denies them, it is not a genuine such discipline. ${ }^{56}$

All this has not remained hidden in Germany. The "unmasking" of valuation, although it appealed to a generation led astray by an extravagant and perverted valuation - in which Heidegger had prominently joined-led to a vigorous counterattack that unmasks the "unmasking," tries to bring reason to bear against the dialectic of axiological nihilism. It attempts to disentangle the mesh of para-, caco-, pseudo-, and etymo- logisms ("Umwortungen," which means "transwordings"), to clean up the deposits of the logorrhea, and to penetrate to the essence of value.

In the forefront of this hygienic task force stands F. J. von Rintelen ${ }^{57}$ whose value realism, on the basis of historical scholarship, ${ }^{58}$ focuses the clear light of 
classical German tradition — of G. W. Leibniz, Immanuel Kant, and especially Johann Wolfgang von Goethe - on the devastated science. Value and being not only do not oppose, they complement each other. Value, like being, represents an objective order: it is a spiritual content (Sinngehalt) that can be realized as goal of conscious or unconscious striving in various degrees of perfection. As relational value (bonum secundum quid) it is utility and related to human subjectivity. As intrinsic value (Eigenwert) (bonum in se) it is objectively real, part of an ontological order and subject to a value logic, an axio-logic, which philosophy's task is to determine. The historical reality of value can be understood in a vertical-horizontal pattern, the first in the dimension of real value (Real-Wert), the second in that of ideal value (WertIdee). Real value is value realized in historical situations, in various depths, depending on the degree of fulfilling the ideal in question. Ideal value gives the breadth of value in horizontal variety and differentiation, which may or may not be realized in a concrete historical situation. The aims of a culture - as well as of an individual-must be to realize as many value forms as deeply as possible. Thus an ontological order of values appears that points to a transcending metaphysical Absolute objectively determined as the Infinite. Heidegger's error, F. J. von Rintelen points out, is his limitation to relational value. Representation (Vorstellen) is not only a negative matter in Heidegger's sense, but of positive significance when a spiritual content is being represented. More deeply, von Rintelen brings to bear against Heidegger the whole philosophia perennis, against which Heidegger tried to erect his own counterorder. Von Rintalen's way, as it was expressed felicitously, is a highway (Höhenweg), as against Heidegger's forest trails (Holzwege $)^{59}$-a highway that overlooks the jungle in which Heidegger makes his ceaseless and fruitless rounds "auf dem Holzwege," lost in the underbrush.

Some of Heidegger's friends, meanwhile, whom we may call semi-anti-axiologists, are busy on Waldgängen (forest promenades) trying to chart the woods from the inside, finding clearings and rational picnic spots ${ }^{60}$ in so far as metaphor is progress beyond contradiction. We find the same tortuous development toward rationality from Heidegger's ontologism as we found from Alfred Ayer's and Ludwig Wittgenstein's positivism. As Stephen E. Toulmin's and others' retail rationality was progress beyond wholesale irrationality, so E. Jünger's and others' attempt at clearing the woods is progress beyond getting lost in the underbrush. As the naturalistic position was a thoroughly rational accounting for things that are valuable - even though not of values - so von Rintelen's is a thoroughly rational account of valuesthough not of Value itself. Von Rintelen reproaches the Heideggerian existential philosophy as formalistic, and rightly so, for it is formalistic in the sense of playing linguistic games ("Versteckspiel," hide-and-go-seek) and making the best (and the worst) of the lack of content of abstract philosophical language. It is analytically formal, but it is not synthetically formal in the definite and rational sense in which I use the term. While von Rintelen's alternative to the game character of existential philosophy is material value statements (analytically material in my sense), my alternative is formal value statements (synthetically formal). Von Rintelen's alterna- 
tive leads to values while mine leads to Value. Both stand in opposition to the "affected extremism" and material irrelevancies of Heideggerian philosophy. ${ }^{61}$ But the values von Rintelen recounts, being spiritual rather than naturalistic, mirror much closer the nature of Value than the naturalistic naivetes.

While von Rintelen brings to bear against Heidegger's counterorder the order of classic tradition, other writers delve with the same penetration into the nature of rationality as Heidegger into that of irrationality. Hermann Krings ${ }^{62}$ deepened Truth into Integrity (Lauterkeit). Integrity, the mutual correspondence of essence and existence, is the ontological dimension of Truth. The ontological dimension of Falsehood is the Demoniac. The Demoniac tries to erect, against the ontological order, a counterorder and realize a non-essence, an ontological monstrosity (Unwesen), in the light of which reality appears distorted, out of place, out of joint-and horrible (ent-setzt).

What I said of the Italian is true of this ontology: it is a model on which formal axiology will have to prove itself; as such it is a profound suggestion of a future logic of value and a proof of the essential rationality of the value world. This rationality is expressed in many variations all over the world, from the profoundly original creation just discussed, to the modern restatement of age-old axiological insights, such as Aristotle's and Plato's virtues, or the Indian purus rthas.

Engelbert Gutwenger, ${ }^{63}$ in an original combination of Aquinian and naturalistic elements, brings the notion of perfection up to the date of an empirical age. Value is always value-for, relational value. This value relationality is of a causal nature such that the thing or person in question is being perfected (vervollkommnet). Perfection is actualization of the potentialities inherent in the thing or person. Whenever a thing acts destructively it does not have the value relation. The definition of value then is: perfecting causality (vervollkommnende Kausalität). The genus of this definition is "causality," which may act either constructively or destructively; the species is "perfecting," which limits causality to the essential nature of value. The Aquinian element of the definition is the species, while the naturalistic is the genus. We may also call it the Kantian or categorial aspect and regard the definition as similar to McCracken's, with scholastic overtones like Gustav Siewerth's. ${ }^{64}$

The Platonic restatement is found primarily in German Switzerland. Hermann Gauss $^{65}$ applies the Platonic triad of Truth, Beauty, and Goodness as a pattern of kinds of lives, each of which is supreme in its kind. His is a commitment to a vital consistency, the total of all these commitments forming the absolute value of life in the Eternal. In Fritz Medicus ${ }^{66}$ the Platonic position is reformed in the direction of Ortega y Gasset and Recaséns Siches: philosophy, in contradistinction to science, which is primarily the work of the intellect, appeals to the whole person, trying to elicit in us a conscious awareness of eternal, supra-temporal values. Beyond the Platonic triad of Truth, Beauty, and Goodness he recognizes a fourth value, Justice, which regulates human social life. The recognition of values is for Medicus, too, an essentially religious act, although he admits no religious "value" alongside or with other values. Values permeate the whole of human existence and are presupposed 
wherever there is thought and action based upon thought. The mission of philosophy is to make the unconscious recognition of values conscious and by doing so to give value-judgments a coherent structure.

Unfortunately, Medicus does not tell us the principles on which the value realm should be structured. We meet here the inherent limit of any ontological treatment of value: lacking formal principles, ontological axiologist can base the structure of the value realm only on analytic guesses, vaguely inspired by the implicative power of material concepts. Since this power is endless - every implication implies another, implying a third, implying a fourth, and so forth - and ontological materiality has no natural ground at which thinking can come to rest, as has naturalistic materiality in empirical observation, the ontological axiologist is like a diver into infinite depths. He must either halt at a predetermined point or else just come to rest at some point out of sheer exhaustion; like Frederich Schiller's Diver, he will never be satisfied, no matter what he brings up from the depths, and will always delve back again, only to meet with more frustrations.

Paul Häberlin, ${ }^{67}$ after exhausting all ontology, comes to the conclusion that in order to be able to speak of values at all we must go beyond "being" and postulate a "ground" of all Being, which, however, must not be dissociated from Being, but from which Being derives its ultimate meaning. Hence, Häberlin adds somewhat whimsically, knowing the meaning of Being we know that of the ground-which brings us back to ontology, but also makes the "ground" superfluous. This is an ingenious device to stop our fall into the depths-an ontological counterpart to Nowell-Smith's trapdoor. If we follow Häberlin's direction to the depths, we either find, in the manner of Frederich Schelling, the Urgrund as the contradictory of Being (and hence, at strategic moments, obstructing the meaning of Being -as Disvalue) or else as the vindication and source of these meanings, as Value. In the first case, we must ask what that is from which both Being and Non-Being have split, and in the second case on what grounds the ground of Being derives its meaning. In both cases we are led to an infinite regress. No matter how we turn, then, ontological value thinking can never possibly find a satisfactory foundation either for Being or for Value. All ontological constructions are in the last resort projections of the implicative method, reifications of the mind's incapacity to grasp the nature of reality and of value by analysis. Ontological value thinking is always material and never formal, always of that which is valuable but never of that which makes it so. As does naturalism, it presupposes the value nature of what it calls value and thus begs the axiological question. Moore, therefore, rightly classified it with naturalism as committing the "naturalistic" fallacy.

Eastern axiology, especially Indian, is in all respects very close to European value metaphysics; it only elaborates more its humanistic emphasis. The ontological direction is thus tempered not by greater cognitive insight but by greater pragmatic relevance—akind of "transcendental pragmatism" that becomes powerfully manifest in the life and work of Mahatma Gandhi. That an ontological axiology of this kind could become practically efficient in India confirms my thesis of the correspondence 
of culture and axiological form. ${ }^{68}$ In the still pre-technological and to some extent medieval society of India, a philosophy could become morally and politically efficient which in form, though not in content, would be an anachronism in the West. Compare the respective efficiency and influence of Gandhi in the East and his master Henry David Thoreau in the West.

Axiology, the conscious pursuit of Value (phala-prāpti), is one of the two divisions of Indian philosophy, the other being the discovery of Fact (artha-parischitti), which entails the first. The ontological basis of Indian axiology is suggested by the meaning of the Sanskrit word sat, which means both "real" and "good," while the pragmatic teleological direction finds expression in the term bhavya, meaning both "future" and "what is auspicious," suggesting that the best is yet to be.

The Sanskrit term for Value is ișa, "the object of desire"; its opposite is dvișa, "disvalue." Value is what we aspire for, what is to be realized, and what is possible of realization, $s$ dhya: what is "rationally willed." What is desired and what ought to be desired are both Values. Purușartha means "human values": our conscious pursuit of values. Both human beings and animals seek satisfaction of their natural impulses, but human beings alone seek their conscious satisfaction. Purușärthas are, therefore, values consciously pursued or Human Values.

Analogous to the four Greek cardinal virtues, Indian though recognizes four cardinal values: Artha, Kāma, Dharma, and Mokşa. Artha (economic value) and Kãma (satisfaction of desire) are regulated by Dharma (moral value). The Mimāmsaka School in Indian philosophy considers that Dharma is an intrinsic value, a value that is an end in itself. Otherwise, the Mim msakas say; Dharma, which is more exalted than Artha and Kāma, becomes inferior and utilitarian like Artha and Kāma. Like Kant, the Mimāmsakas teach a doctrine of respect for the Moral Law, its absoluteness, and its unconditional nature. The philosopher Samkara rejected this view. He regarded it as psychologically unsound since it assumes that voluntary activity is possible without some end, or that it becomes its own end (svayamprayojanabhuta). Such a theory, said Samkara, reduces the gospel of duty to a gospel of drudgery: Devotion to duty is present toil, dereliction of it future evil; so whether a person does his duty or neglects it, his or her lot is always trouble in life. For this reason the Mimamsaka view of Dharma has not prevailed in Indian thought.

Dharma is an instrumental rather than an intrinsic value, in a "lower" and a "higher" sense. The first is its utilitarian aspect: moral Goodness will eventually and very slowly - like God's mills in the West — bring success and abundance (abhynd$a y a)$. The second is its strictly moral and usual sense: the purification of the agent's character (sattva-suddhi). This is brought about through the active performance of the duties of our station in life, the work that is near at hand, without egoistic intention or motivation (niskāmakarma). It is freedom from the lower self, samnyāsa or renunciation, but it is not negation of the world. Indian thought teaches self-affirmation in discipline and self-negation in service to others, but not world negation. Dharma is a necessary and sufficient condition to reach Moksa, the Highest Good, or Intrinsic Value, an existential state of Being, of growing into the larger Self, an experience of 
bliss (ānanda). Indian axiology culminates in a kind of existential or transcendental Hedonism (Jivan-mukti, "liberation during life"). Moksa is not gaining anything new but is the recovery or recollection through dhyaña (meditation) and yoga (moral and spiritual discipline) of that which is intrinsic to one's self. As such Moksa is what is truly "normal." It is "ever-attained," siddha, against the other purushartas which are sadya, "to be attained" or extrinsic.

This basic axiology is applicable to specific value experiences, aesthetic, political, and such, in all of which is found ananda, the experience of delight in being. Thus, ānanda is the clue to the mystic aesthetics of Vedanta: the saints are the greatest artists for they, like Søren Kierkegaard's "Knight of Faith," ${ }^{99}$ have mastered the art of living; here and now they experience the delight of existence under all circumstances, above and beyond the routine and the imperfections of life ("avidyā kämakarma," "ignorance, blind desire, entangling action"). Ananda is equated with Brahman, the one reality without a second, and the universal inner harmony. It is a characteristic of enlightened individuals that they experience directly and realize by their active living this delight of existence. ${ }^{70}$

Indian thought includes a highly elaborate ontological axiology that overcomes the vagueness of analytic concepts by devising an exact -and exacting - method of moral living. In some sectors of Indian society and in some periods of Indian history, especially the epochal life and work of Gandhi, this philosophy has shown its social efficacy. It was continued in the vital economic sector by Acharya Vinobe Bhave. His tenets - that economic goodness and ethical goodness imply each other and that social revolution means human valuation-are stated for and within the context of the West by Robert S. Hartman. ${ }^{11}$ In other sectors and periods it has failed. On the whole, considering the social and political actuality of India, it has failed more than succeeded, though it has probably succeeded more than has Christian axiology in the West. Both in the East and the West, therefore, an axiological pattern must be found that will lead to moral action as thoroughly as the mathematico-empirical pattern has led to technological action. Western people cannot be brought to moral action in the massive Gandhian sense by the medieval pattern of contemporary axiology, or by individual exercises such as yoga and dhyana. These patterns will not long remain efficient in the progressively modernizing Indian society. In both the East and the West, a formal and synthetic pattern is needed that contains its own method of action, not only for select individuals, but for all people as part of their rational living.

Ontological axiology, in fusing Value with Being, is an obstacle to such a development. Instead of explicating the fundamental relation of axiology, that between fact and value properties, it collapses it, fusing both kinds of properties in one great reifying, substantializing hypostasis. In phenomenological axiology we get closer to our goals for there the hypostasis at last separates cleanly, or as cleanly as hypostatically possible, the two realms. 


\section{B. Phenomenological Empiricists}

Phenomenological empiricists experience cognitively a value realm sui generis, independent of and different from the ontological realm of Being. They are pure axiologists in the sense that they do not confuse value with anything else, either physical or metaphysical, even though they hypostatize value into Value, ought into Ought, and so on. The fundamental axiological relation becomes in turn hypostatized, as one between Being and Value, Is and Ought, and the like. The prototype of this phenomenological hypostatization is the great work of the first post-Moorean period, Nicolai Hartmann's Ethics. ${ }^{72}$ The fundamental axiological relation here becomes a cosmic tension between the ontological and the axiological realms. Both these realms are for Hartmann aoristically separated, and between them stands the synthesizing entity, the moral subject, converging the whole tension of the two worlds toward her or his own heart-the Arnold Winkelried of the axiological battlefield.

The attitude of the subject to the Ought is the central point in the ethical problem.... The subject as a practical agent is the intersecting point between two heterogeneous determinations or powers; at the same time it is the battlefield where these powers clash with each other within the one real world. Hence the restlessness in the nature of the subject, his continued confronting of decisions. Thus it comes about that the Ought, although it is not rooted in the subject, but confronts him as a positive claim, nevertheless, as a positive tendency in the real, can attach itself only to a subject, and can determine reality only through a subject. ${ }^{73}$

The subject is the knight of the Ought, the standard-bearer of the potential in actual reality. The efficacy of axiology, which in the value ontology of Indian thought is guaranteed by a method, is guaranteed in Nicolai Hartmann's value phenomenology by our human affinity to both the ontological and the axiological realms. The axio-ontological structure of human persons brings the hypostatized axiological relation down to earth. The whole process is somewhat fanciful, as befits a brilliant analytic presentation, for the necessary lack of precision of the analytic method can be made up for brilliantly either by artful verbal convolutions, as in Heidegger or the Wittgensteinians, or by a poetic imagination that entrusts to metaphor what formal precision would entrust to logic.

The realm of the Ought is not one of quietness and serenity; it is one of striving and dynamic struggle. Hartmann's precursors as architects of the ideal world are Plato, Aristotle, the Manichaeans, Jacob Boehme, Friedrich Schelling, Eduard von Hartmann, Henri Bergson, and, in particular, Arthur Schopenhauer. Hartmann's values, like the Platonic ideas in Schopenhauer, are "incurably gluttonous."74 The Ought "forces its way into the indifference of the real, in that it gains a power over one of the worldly entities." 75 It grips a person and makes him or her its subject, as does Zeus the unsuspecting Ganymede. Hartmann's ideal Ought-to-Be has more 
Olympic qualities, being "of course as indifferent to the subject as it is to existence....But the positive Ought-to-Be is not indifferent; for its unfoldment in the existing world does depend upon the subject." ${ }^{16}$ The division between the ideal and the positive Ought-to-Be is an artificial construction within Hartmann's axiological metaphysics, necessary in order to combine its Platonic aloofness with its Schopenhauerian dynamics - to explain the efficacy of the axiological realm. "The positive Ought-to-Be does not lie within the ideal realm. It issues thence, but extends into the real; and in so far as it is a determining factor there, its activity is a real creativity, a bringing forth." of Ganymede or passionate lover of Leda and Europa, the ideal and the positive Ought-to-Be, Janus-like, a kind of Olympic Dr. Jekyll-and-Mr. Hyde, rules Hartmann's ethical cosmos.

This construction is interesting but unconvincing. The "ideal Ought-to-Be" is a fiction, set up for the sake of an ideal position that is not consistently maintained. The entire realm of values is a dynamic, throbbing realm; its ideality is a dynamic ideality, corresponding to the dynamic reality in which it becomes active. Conversely, the real corresponds in its creative activity to the same qualities of the ideal: "The real dynamic or the finalistic series corresponds to the ideal dynamic or the Ought-toBe." ${ }^{18}$ To maintain the artificial separation between the Platonic valuational realm and dynamic reality, Hartmann reverts to Aristotelian language, setting up the ideal as the prime-mover, unconcerned and unmolested in the yonder realms, yet somehow causing the dynamic flux of the ethical cosmos. "Values are genuine 'first movers' in the Aristotelian sense; from them proceed creative energy, productivity fashioning actualization. Value is the power that stands behind the energy of the Ought-to-Be."'79

Hartmann's theory is a perfect example of the hypostatization of value. As in the ontological reification, the logical relations of formal axiology appear here in a magnifying mirror and must be dehypostatized, cut down to size, re-translated into relations of the logical matrix from which the poetic imagination of the philosopher lifted them. The "ideal Ought-to-Be," then, becomes the simple logical relation between a thing lacking and a thing having its definitional properties-for a thing that is a member of the class $\mathrm{C}$ and lacks some of the properties of $\mathrm{C}$ ought to have these properties: the class concept serves as norm for the thing's possession of its properties; the "positive Ought-to-Be" becomes the rules of application of formal axiology.

G. E. Moore saw the phenomenologically unique character of value, but he abstained from fanciful elaborations of this intuition and limited himself to stating the logical implications of such uniqueness. But since Moore merely stated and did not elaborate this uniqueness, the logical implications seem to hang in the air, like the grin of the Cheshire cat. For this reason Moore found more critics than followers. Among the followers are Thomas Hill, as previously mentioned, and R. Corkey. ${ }^{80}$ Nicolai Hartmann and Max Scheler, who fill in the phenomenological hull of value, became heads of schools and subjects of a large monographic literature. ${ }^{81}$ The paradox of the phenomenological position is either to be formal and then lead to 
logical implications that seem empty, or to be material and then lose itself in metaphors.

In his later axiological writings, which we may count to the second postMoorean period, Nicolai Hartmann's analysis became sharper and turned away from his original hypostatizations. He gave us a deeper analysis of teleological thinking, supplementing his account of the "threefold finalistic nexus" in the Ethics, ${ }^{82}$ and a clearer insight into the relations between the "positive Ought-to-Be" and the human will, and the will and moral feelings. This dehypostatizes, to a certain extent, the Ought-to-Be and throws light on the difficult distinction - not possible in any other axiological position - between the emotive and the valuational.

Value feeling has an entirely different relation to value than the will. The will is free with respect to values, it is not forced to follow the moral command.... The feeling of value...is not free in this respect, it is quite clearly forced by the values: once it has grasped the meaning of a value it cannot feel differently or take a position other than the value commands. It cannot regard good faith as wicked, cheating and deceit as honorable. It can be value-blind, but that is an entirely different matter: in this case it is not responsive to values, and does not comprehend them at all ${ }^{83}$

- like a person who is color-blind, or unmusical, or lacks mathematical talent.

Hartmann makes clear that the value capacity is a rational one; thus the Forderung, the claim of values upon persons, is a rational claim. Only his ontological bias prevents him from going a step further and stating that this is so because the value realm is itself a logical order, a value-logical or axio-logical rather than an onto-axiological one. It is, as Ortega y Gasset made clear from the phonomenological view and Margenau from the scientific side, a quasi-mathematical order, that is, an order as formal as mathematics but whose axiomatic content is not that of Number but that of Value. The "claim" of the value realm, then, is the same kind of claim as that of mathematics, of logic, and of any other formal discipline: the claim upon our rational understanding.

In Hartmann's second post-Moorean account this becomes crystal-clear. The validity of the axiological order resides in its rationality; the moral agent only accepts as valid what he (or she)

understands and ascertains; he recognizes only what is clear to him. All appeal to mere authority is impossible. The 'doctrine' given to him must be convincing; the rules of society, the ideals of life of elders and experts, even the 'laws of God' must be convincing. ${ }^{84}$

This convincingness, this intelligibility of the value realm, is the subject matter of all great sociological thought, from Plato through Kant to Scheler; but the mechanics of how this "a priorism of the knowledge of good and evil," this rigorous order 
of axiological insight and its objective validity, ${ }^{85}$ realizes itself in human action is still unknown. All descriptions of it "remain stuck in generalities." approach it by an empirical account of how the feeling of values manifests itself in human situations, ${ }^{87}$ but he does not thereby come closer to the core of the matter; he must, he believes, content himself "with certain fundamental characteristics which have become apparent so far."'8s

Actually, all these characteristics fall into a pattern, like the pieces of a puzzle, as soon as it is recognized that the "a priorism" of the value realm is nothing but the formal nature of value: values constructed, as are phenomena in natural science, as an axiom and developed in a deductive order - according to my preceding proposition (5) given above on pp. 81 and 165. The "chain" of the value realm is then the necessary practical aspect of this order. The various fragments of value insight that the phenomenological account assembles are like pieces of a broken mirror that reflect the formal nature of value. Formal axiology must present the mirror in its wholeness.

The phenomenological position was developed in the second post-Moorean period in many directions. Johannes Hessen ${ }^{89}$ gives the following "moments" by which Being and Value differ: (1) Value is irreal or ideal being (validity); Being is real being (existence); (2) Value is abstract, non-sensory; Being is concrete, sensory; (3) Value is normative, an ought; Being is actual, an is; (4) Value is polar, positive and negative; Being is unitary; Negative value is still value, but negative Being is no more being. In a formal translation, the confusion of these four moments, based on merely verbal distinction, becomes clear, and the phenomenological position becomes: (1) Both the value and the fact order have a real and an ideal component. The ideal component of the value order is formal axiology; the real component is the world of value phenomena. The ideal component of the fact order is mathematics; the real component is the world of natural phenomena. The difference between the two orders in the ideal realm is that between formal axiology and mathematics; the difference between them in the real realm is that between descriptive (value-making) and value properties, the fundamental axiological relation. (2) Value is abstract, non-sensory while Being is concrete, sensory. The difference is the just mentioned one, the fundamental axiological relation. The "abstract" nature of value is its second-order quality as referring to the totality of value-making properties. (3) Both Value and Being are normative and actual, both ought and is. The relation between ought and is depends on the difference between the ideal and the real order. Ought vindicates the requirement of the real order to be organized in accordance with the ideal order. Since both Value and Being consist of an ideal and a real component, both are subject to both ought and is relations. "John ought to be honest" and "John is honest" are both value propositions, and "circles are round" and "circles ought to be round" are both fact propositions.9" (4) Both Value and Being have a polar structure. The polarity is between order and disorder. Actual value is what corresponds to the ideal value order and actual disvalue is what does not correspond to this order. Actual Being is what corresponds to the ideal fact order and actual 
dis-being is what does not correspond to this order. Neither value nor being can be "negative" in the sense of "non- value" and "non-being." Both can be negative in the sense defined, as dis-value and dis-being. ${ }^{91}$ To these four translations must be added a fifth point which follows from these translations: (5) The orders of Value and of Being are parallel. What is value also has being, and in the same degree; what has dis-value has dis-being, in the same degree. Thus a two-headed calf is as little a calf as it has value as one; a square circle is as little a circle (or a square) as it has value as one. What fully is has value as such. With this point formal axiology approaches the classical value ontology. These inherent logical relations come out in value phenomenologies in different ways, so that Value and Being in them oscillate closer to or farther from each other.

Following a model of Eduardo García Máynez ${ }^{92}$ the logical possibilities of the relationship between actuality and the ideal realms of being and value could be represented by three overlapping circles that would give seven sections: (1) ideal being (categorical and scientific ontology), (2) ideal value (categorical and scientific axiology), (3) pure actuality (as possibility of concretion of either or both idealities), (4) the overlapping of the two ideal realms (the value of science and the science of value), (5) the overlapping of actuality with the ideal realm of being (the categorical and scientific cognition of factual reality), (6) the overlapping of actuality with the ideal realm of value (the categorical and scientific cognition of value reality), and (7) the overlapping of all three realms (actuality seen in its ontological and axiological reality).

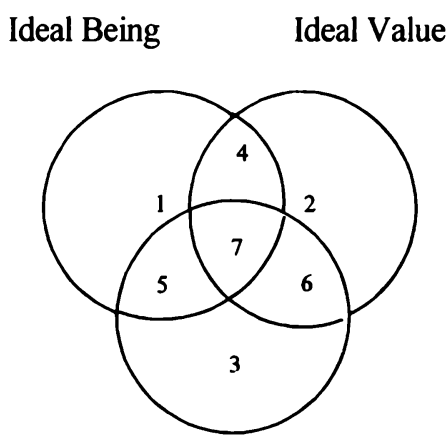

Pure actuality

García Máynezuses this schema to clarify the logical interrelationships between juridical and axiological ideality and juridical reality, that is, instead of the ontological order he uses the juridical order. The three realms then are positive law (juridical ideality), moral law (sociological ideality), and social use (actuality). The three realms again overlap in three circles, forming seven sections of combinations of norms, only one of which is the coincidence of all three realms, and hence valuable legal actual- 
ity. Such coincidence is very rare; indeed, it is in historical reality the exception rather than the rule. The reason, says García Máynez, is

the narrowness or narrow-mindedness (Engherzigkeit) of our value feeling. The cognition of the values which the law is to realize is far from perfect. Furthermore it is not sufficient merely to know these values;... also the norms must be created which in the various legal situations make possible their realization. ${ }^{93}$

The same must be said of the ontological-axiological relation to reality. The solution, I find, is a formal axiology that would bring about not only a valuable ontological, but also such a juridical actuality. For García Máynez, the law is regarded as a means of realizing value; value is normative for the law - a thesis exactly opposed to that of those who, like Stephen Toulmin, Hector Rodriguez, and others, want to make the law normative for ethics. This axiological school puts the cart before the horse and, together with W. D. Lamont and others, uses specialized axiological disciplines as normative for the genus.

Writings in jurisprudence, economics, politics, and so forth, abound with axiological problematic; but most writers understand that the problematic must be solved by a science of axiology normative for their discipline rather than by their discipline serving as norm for axiology. Lacking a formal axiology, axiological writings in jurisprudence cannot be more precise than writings in axiology itself. Hans Kelsen writes in his "conclusion": "I do not know, and cannot say what justice is, the absolute justice for which mankind is longing....' My' justice, then, is the justice of freedom, the justice of peace, the justice of democracy, the justice of tolerance" 94 -in other words, the justice that is as undefined as are all these other value terms. It is strikingly obvious from such "conclusions" that what is needed is an overall system of axiology.95

Axiological significant legal studies have been produced by many writers. Georg Cohn pleads for a human-centered existentialist law, and Edmand Cahn studies the "sense of injustice" as the basis for an "anthropocentric law" and probes into moral decisions in the law. ${ }^{96}$ Gerhart Husserl produces a phenomenology of legal cases, and Günter Less and many others discuss the relationship between moral and legal values from the point of view of an objective axiology. ${ }^{97}$ Others like Guido Fasso take a non-rational point of view that assumes a total qualitative leap between juridical land moral values; but Luigi Bagolini takes an intermediate position. ${ }^{98}$ Axiologically significant discussions in political theory are Georges Bastide's study of the political dimensions of value and Sebastian De Grazia's analysis of "anomie"- value chaos integration and disintegration - in society and institutions. ${ }^{99}$ David Easton pleads for an exact political science based on the theory of values, and Jacques Maritain and Fernández del Valle Basave have written value-diffused studies of human beings and the state. ${ }^{100}$ Felice Battaglia, Luis Recaséns Siches, Pitrim Sorokin, and others have produced profound sociological studies of values. ${ }^{101}$ The axiological position of economic theory is discussed by by Walter A. Weiskopf who offers a 
psycho-ethical analysis, and by Gunnar Myrdall who gives a politico-ethical analysis of economic theories. ${ }^{102}$ Some theorists have written relevant methodological studies, and others discuss the distinction between economic and moral judgment. ${ }^{103}$ Value studies in anthropology are found in the writings of David Bidney and especially of Dorothy Lee, ${ }^{104}$ who sees cultures as value patterns expressed in their linguistic and other cultural forms, and who makes anthropological data relevant to axiological insight, and vice versa.

Of the many directions in which phenomenological axiology can be developed I shall only mention those most important for ethics which develop the anthropological and the existential directions, such as Marcel Reding's. ${ }^{105}$ Marcel Reding's axiology is based on the nature of the moral agent, the human person seen as an existential, functional, and ontological structure. Moral value is the fulfillment of human nature in cognition, volition, and love, and in the realization of the dianoetic, ethical, and love-values, all of which rest on the value of Being, the ontological foundation of moral value. The central position of humankind in the value cosmos strengthens the weak point of Nicolai Hartmann's axiology, the lack of connection between the abstract realm of values and the actuality of value realization, but it invalidates much of Hartmann's imaginative structure. The scope of the value realm, for Reding, is the scope of our human value sensitivity and activity. Axiology, therefore, is essentially philosophical anthropology. It is not phenomenology in so far as phenomenology assumes the dominion of value to be determined once and for all. It is, rather, a categorical structure, the categories being those of human value apprehension: distance and proximity, objectivity and subjectivity, transobjectivity and transsubjectivity, determination by feeling or by reason, and material or human realization of values in things or in humans. Although values can become human goals, they are not merely such goals, but are objective matters of human action, corresponding to human nature, and subjectively to be confirmed by human decision. Since they correspond to human nature, their understanding presupposes that of human nature. Human beings are structured totalities, consisting of many levels. Here is the influence of Nicolai Hartmann's ontology —with spirit as the highest level, the locus of human freedom, and a transcendence both horizontal and vertical, in the direction of our fellowman and of God. The concrete totality of all these relations - of human beings to ourselves, to our fellow human beings, and to God-is a concrete situation; it is the locus of value.

A speculative ethics of axiological essences à la Nicolai Hartmann, therefore, is a construction that misses the core of value reality. Each situation has its own inherent valuational content, its value matter (Wertmaterie). This content must be appropriated in three ways: cognitively (dianoetically), actively (ethically), and compassionately by loving inclusion of other human beings and God (agapetically). These three kinds of value belong insolubly together with love, highest in the hierarchy of moral value, and God, the highest object of love; the dianoetic values in second place, and free intellectual occupation with the divine as the second highest value; and ethical value in third place, as control of life through reason. Those who 
regulate their lives in conformance with their love of God and their insight into the divine realize the third highest value. These values are efficient because they are inherent in human persons. There is no absolute Ought or similar construction, yet, the various classes of value and the height of their rank are not indifferent to one another but are "implicatively" connected. This connection is that contained in the concept "human being." This analytic concept rules this kind of axiology, and the axiology is the implicative elaboration of this concept. Another view of humankind, for example, the materialistic, would lead to a different axiology, but on the same basis and with the same justfication. Only a formal definition of human nature can break the connecting circles of such axiologies. So far the competing schools do not realize their similarity, indeed, their identity of method, and that the bitterness of their polemics is due to their being brothers.

A good example of such a fratricidal axiology is that of Eliseo Vivas. ${ }^{106} \mathrm{His}$ conclusions are the result of a polemic against naturalism rather than a development of anthropological phenomenology. Values, for Vivas, have objective existence. Value judgments refer to a quality of an object and not to subjective qualities such as satisfaction, fulfillment, or pleasure, which are themselves endowed with value. Confusing the value of an experience with the value of an object experienced is a form of the subjectivistic fallacy. We human beings participate in the value realm like any other object, but unlike an object, we not only have but are values, and indeed supreme values. A moral person is a system of values; a decision is a moral decision if it sustains the constitutive values the person has adopted as her or his own. The ground of moral authority is not in the will or desire of the person but in the objective values he or she has adopted. Among these values is one which, when held as supreme, turns the moral person into the ethical person: the value of other persons. This value has an onto-axiological status all its own: the worth of persons is independent of the worth or order of rank of the values they have adopted and that constitute them. Here, too, agape crowns the axiological structure, and the Gospel becomes the final vindication of philosophy.

From a methodological point of view, the Gospel ought to be a subject matter of value theory rather than value theory being a subject matter of the Gospel. Value theory ought to indicate the Gospel rather than the Gospel indicating value theory. Such rational human vindication may well be the only way of making the Gospel efficient. The vindication of axiology by the Bible, then, compares to the Aristotelian explanation of logic by natural process rather than to the explanation of natural process by logic. Axiologies that culminate in religion, then, are in danger of becoming sermons and failing in their mission to make religion an axiological method. Although such axiologies are often beautiful to read, they turn out to become subject matters of axiology rather than axiology - valuations rather than theories of it.

Intellectually more exacting than anthropological phenomenologists - who can take cover under the infinite implicative content of the concept "human being"- -are those philosophers who turn axiological phenomenology in the existential direction, 
perhaps because the concept "existence" is bare of content and forces the thinker to original construction.

Daniel Christoff, ${ }^{107}$ in a most acute discussion, uncovers the temporal-extratemporal aspect of the fundamental axiological relation. The factual properties of the thing are in space and time, while the value properties are not. Hence, this distinction must appear in the epistemological relation between actual recognition of a value and the value's own phenomenological status. When I recognize an ideal as an embodiment of the Idea of Goodness, I recognize a value whose signification lies outside of time. The act of recognition is a temporal act, but what is recognized in it cannot be described in temporal terms. An ideal recognized and accepted helps me in my task of transforming reality; yet, in holding fast to something whose significance is "beyond" time and that is not subject to temporal conditions, my existence in timeas described, for instance, by Heidegger-is cut in two: the recognition of an extratemporal value stops the continuous flow of time and elevates us above the sphere of mere becoming into that of "being." This goes for any act of valuation, whether aesthetic, ethical, or epistemological. The creation of a work of art is a temporal act, but the ideas of Beauty and Harmony symbolized in it cannot be understood in temporal terms. The same is true of a theoretical judgment. Arriving at a judgment is an event in time, but the meaning of the judgment is not the product of a temporal act; it stands in its own right, having a signification independent of events in time.

Christoff, accordingly, does not believe that in acknowledging values we behave in a merely passive manner, as might be suggested by some representatives of the phenomenological school. Judging aright, adopting an ideal, and seeing beauty in this, are acts of creation. Christoff, like Reding, and for similar reasons (the spontaneity of human freedom) goes beyond the presuppositions of phenomenology and its reduction of philosophy to apprehension of mere essences and their interrelations. In pointing to the independence of the "realm of meaning" from the temporal acts by which these meanings are made conscious, he leaves behind the existentialist position of thinkers such as Jean-Paul Sartre and Gabriel Marcel.

For formal axiology the distinction made poses a most profound problem: that of finding a formal pattern which corresponds both to the temporal order and to the extratemporal order. If the temporal order is regarded as that of succession, in the sense of G. W. von Leibniz, and mirrored, in the sense of Immanuel Kant, in the series of natural (or rational) numbers, these numbers would represent the temporal order. The extratemporal order, then, would be represented by a series that appears as a cut in the series of natural numbers, just as a value decision, according to Christoff, appears as a cut in the series of temporal events. The series which appears as such a cut in the series of rational numbers is that of the real (non-algebraic irrational) numbers; the formal pattern corresponding to Christoff's distinction is then that between the various powers of transfinite cardinals. Here we see how acute analytic patterns can bring out isomorphisms with synthetic constructions that appear in formal axiologies. 
The phenomenon of choice, which in naturalistic axiology leads to the finite mathematical patterns of game theory, leads in phenomenological axiology to patterns of transfinite mathematics. Whereas in the naturalistic view the fundamental axiological question is begged - why is choice a value and indeed the value phenomenon?in the phenomenological view freedom appears, if not as the at least as $a$ fundamental value phenomenon by the definition of value itself which, whatever else it may be, certainly is not fact-and fact is spatio-temporal. If spatio-temporal determinations are natural properties in the sense of G. E. Moore, then value properties are not spatio-temporal. Value properties, depend only on spatio-temporal properties (according to Moore's second proposition true of value); and this relation, rather than the difference between temporality and value, is the profound problem to which Christoff addresses himself.

The distinction between the finite and the infinite in connection with axiological choice appears prominently in the value philosophy of Gabriel Philippe Widmer. ${ }^{108}$ Values are not produced by our consciousness but are independent of it. They cannot be wholly transcendent, but they are subject to our conscious choice. We must decide among values. In order to do that, it will not be enough for us to choose among a given finite number of them; rather, our souls must be open to the infinite and its unlimited possibilities. Values are, therefore, something like a go-between (an "entre-deux") between human consciousness and God. They have their foundation beyond human consciousness, but they cannot become actual without it. Consciousness reflects on the ways and means by which values can be realized in time.

Like Andre Lalande, who distinguishes between "la raison constituante" and "la raison constitutée" in his attempt to explain the possibility of knowledge, Widmer distinguishes between "la valeur constituante," the basis and structure of value beyond our consciousness, and "la valeur constituee," the process of realization of value within and through our consciousness. This is the distinction that $F$. J. von Rintelen calls Wert-Idee and Real-Wert, Nicolai Hartmann the ideal and the positive Ought-to-Be, and formal axiology the theoretical pattern and its application.

Phenomenological axiology, in its more detailed elaborations, leads to descriptions of the value realm that give its structure in large outlines, as do maps of an unexplored continent. Ontological axiologies help to fill in certain features, and even the guesses of naturalistic axiologies give hints at the contents of the continent. Needed then is a detailed cartographic surveying; this cannot be undertaken by material axiologies, either naturalistic or non-naturalistic, but only by formal axlologies whose first concern is sharpening and creating geometric, geodetic, hypsometric, topographic instruments for the job.

\section{Non-Naturalistic Formalists}

Our spectrum of value theories has brought out similarities in value thought throughout the world which, if taken seriously, suggest an underlying value logic, as is held by A. C. Ewing, F. J. von Rintelen, and others. The acute ontological and phenome- 
nological investigations of thinkers like Hermann Krings and Daniel Christoff suggest sharp and profound intellectual differentiations of the value realm, which should mirror distinctions in a formal pattern as precise as mathematics.

Non-naturalistic Formalists try to develop such a pattern. They accept all five of my original propositions about values (page 15 above) and believe it possible to devise a formal axiological system that may be applied to value reality as mathematics is applied to natural reality. Not all thinkers of this kind have this vision in dual clarity, but in all of them it is, if not explicit, at least implied. The same is the case with some thinkers discussed earlier, such as H. P. Rickman and his ingenious solution of the emotive-descriptive dichotomy as arising from the logical distinction between theory and application, von Rintelen and his distinction between Real-Wert and Wert-Idee, Herbert Feigl and William Kneale in projecting an objective system of axiology, and others who might agree with $\mathrm{Ch}$. Perleman that since value disagreements are in the form of argumentations, a general theory of value presupposes a general theory of argumentation and a "logic of value judgments."

A consistent logic of value is the more necessary as without exception all the theories discussed so far lack a general principle of structuring the value realm-if, indeed, they recognize such a realm at all. How to bring about this logic of value is a more formidable problem because value terms are not only "polyguous," to use Paul Edwards's word, but any term, as Maria Ossowska ${ }^{110}$ makes clear, can under certain conditions become a value term. To say that poppy is red is stating a fact; to say to a lady that her nose is red is stating a value. Thus, no matter whether we define value by characteristic terms or by emotive impact, difficulties stand in the way that must be cleared away before a consistent theory is attempted.

Yehoshua Bar-Hillel," in a discussion that might be used to solve Maria Ossowska's dilemma, tries to give a logical foundation to the contextual or "performatory" school. Similar to Ingemar Hedenius and J. L. Austin (see Chapter Five), he suggests distinguishing, in the comprehensive group of indicative sentences, between indicative sentences that are context-independent and those which are contextdependent. Indicative sentences that are context-independent are those in which knowledge of the context is not necessary for understanding the information presented, while in context-dependent sentences knowledge of the context, in its entirety or in part, is essential for this purpose. An example of the first type is, "All ravens are black," and of the second, "I am hungry." Bar-Hillel shows that with regard to context-independent sentences, which he calls statements, one may speak of the truth and extension of the sentence without concern for the different contexts in which it appears or is likely to appear. Sentences in natural science are generally expressed by means of statements of this sort. In the case of context-dependent sentences, the truth or extension of the sentence depends on its context, which can be different in every occurrence of the same sentence. All ethical sentences, he believes, if not all value judgments, are context-dependent. Both Aristotelean and modern logic, he believes, have closed their eyes to this distinction. 
This may not be quite true. Singular concepts seem to be context-dependent, and insofar as logic has dealt with them it may be said to have dealt with contextdependence. But the categories of context-dependence and -independence seem to lack logical importance as long as they are not logically structured as formally synthetic rather than materially analytic concepts. Most attempts at structuring context-dependence so far have been of the materially analytic kind, for example, Nowell-Smith's (see Chapter Five).

The solution of finding formal isomorphisms for context-dependence has so far been attempted with reference to the law. The question is whether the law is a genuine synthetic pattern; the investigations of Eduardo García Máynez and others have shown that it is not, but depends itself on formal deductions. John W. Davis and I have shown that singular concepts have a formal pattern. ${ }^{112}$ Georges Kalinowski ${ }^{113}$ tries to show that normative statements follow a logic analogous to that of the modal propositions of Aristotle. G. H. von Wright ${ }^{14}$ developed a detailed model logic, including "deontic modality," ontology and logic of legal norms ${ }^{116}$ have, according to Norberto Bobbio, ${ }^{117}$ fundamental importance for any normative discipline.

There is no dearth of programs for formal axiologies. Deontic logics are not formal in the synthetic sense, but only "fornal" in the analytic sense. But there are prospects for truly formal axiologies. They fall into two groups, the first based on the logic of the term "better." the second on that of the term "good." Both groups make use, implicitly or explicitly, of the notion of the fullness of logical being and thus are direct developments of what I called axiologia perennis. The first group uses the notion more negatively, the second more positively. The first takes as axiomatic the relative emptiness, the second the relative fullness, of logical beings. The axiomatic of the second group is more comprehensive than that of the first and includes it; it defines the fundamental relation that the first group leaves undefined.

That a formal relation of betterness may underlie all value judgments was long ago seen by A. P. Brogan ${ }^{118}$ and is suggested by the various theories making use of this relation such as Lamont's, Glansdorff's, and Davidson's et al., discussed earlier. E. T. Mitchell ${ }^{119}$ develops Brogan's suggestions into a full-fledged system of ethics, that is, an ethics based on a strict sociological framework. The theory begins with "better" as an undefined term and defines "good" as "that whose existence is better than its non-existence." With this definition, says Mitchell, we have a frame of reference of far-reaching importance that transforms value theory into a science. For, as with every theory, value theory becomes a science when it assumes the form of a coherent logical structure that arranges its fundamental concept and accounts for its phenomena consistently. Let $A, B, C \ldots$ symbolize objects between which there exists the relation of "better than" or "worse than." These objects are "values." We then have as Primitive Term: better than, and as Definitions:

$A$ is worse than $B=B$ is better than $A$. This defines "worse" as the converse of the relation "better." 
$A$ is equal (in value) to $B=A$ is not better than $B$, and $A$ is not worse than $B$. $A$ is good $=$ The existence of $A$ is better than the non-existence of $A$. $A$ is bad $=$ The existence of $A$ is worse than the non-existence of $A$, or The non-existence of $A$ is better than the existence of $A$.

Postulate: If $A$ is better than $B$ and $B$ is better than $C$ then $A$ is better than $C$. This postulate states the transitive nature of the relation "better than" and is the basis of the serial character of value and hence of the notion of a scale of values. ${ }^{120}$

Similar to the scale of good things is a scale of bad things. If the non-existence of $M$ is better than its existence, then $M$ is bad. If $N$ is worse than $M$, and $O$ is worse than $N$, and $P$ worse than $O$, and so on, then these items are arranged in a scale of worseness. The dividing line between good and bad consists of those things that are indifferent. Thus we have a scale of values arranged in serial order above and below the Zero point of indifference.

"Ought" and "duty" are defined in terms of "possible." "X ought to exist $=X$ is possible and $X$ good....X is a duty $=X$ is possible and $X$ is the best alternative,"121 but "alternative" is not defined strictly in terms of the system. Another possible definition would have been " $A$ ought to be like $B$ " = " $B$ is better than $A$ " and " $A$ ought not to be like $B$ " = " $A$ is worse than $B$." In other words, "ought" could be defined, in terms of "better." If $A$ is worse than $B$, then $A$ ought to be like $B$, but $B$ ought not to be like $A$. "Like" could be defined as "having the same class properties as."

The serial nature of value leads Mitchell to the question of the highest good and the notion of a class of transfinite values. The fact that empirically known values can be arranged in a series ordered by the relation of "better" and "worse" does not exclude the possibility that there are infinite values conceivable by reason, lying over and above finite relational values, and not belonging to the series. "The Good" of Plato and the other eternal forms as conceived by Plato would be examples of such transfinite goods, as would be the Absolute of Spinoza, the Eternal Consciousness of T. H. Green, and similar "supreme goods." All of these can be conceived of as infinite in the strict sense of being transfinite. Just as the scientist uses the isomorphism of a set of phenomena with a set of mathematical constructs in order to understand the phenomena, so Mitchell uses a set of mathematical constructs, that of transfinite numbers, to understand a set of value phenomena, "supreme goods." If, he says, the value scale has no highest member, at least there is the class of all goods, and this class constitutes the Good.

On the same analogy, other transfinite values like Truth and Beauty might be conceived of as forming a realm of transfinite values, in exact analogy to the series of natural numbers, which have no upper limit but, as a class, form a transfinite number. The series of natural numbers is formed such that, beginning with zero, each successive number arises by adding one to the predecessor. Since the series has no upper limit, the class of all the natural numbers is an infinite or transfinite number. Similarly, values form a series, and series of series, and the totality of them form 
transfinite values. This isomorphism between value and number makes the notion of transfinite value lose its irrationality and develops it by strictly logical means. It puts meaning and precision into such non-sequiturs as: "the better implies a best," "progressive betterment implies an ultimate goal of perfection," "progress is meaningless without a final goal," and the like. "Better" and "worse" do not imply an absolute good and an absolute evil any more than "earlier" and "later" imply an absolute first beginning and an absolute last end to the time series. But Mitchell does not develop the isomorphism between the time series and the finite-transfinite nature of value in any detail. Had he done so he would have arrived at some of the distinctions made by Daniel Christoff, as mentioned in Chapter Two.

Although Mitchell has not worked out the theory in systematic detail he is able to apply it suggestively to the practice of moral life. He uses for this A. P. Brogan's "Analysis of the Moral Method," 122 which consists essentially of three stages: (1) the survey of alternatives, (2) the analysis of alternatives, and (3) the choice of the better alternative. A moral problem always is a situation presenting alternative choices. "Choice" is the practical term of which "betterness" is the formal meaning. Mitchell compares Brogan's method to Dewey's analysis of the complete act of thought and its five steps, and to Plato's perfectionist method and its two steps-delineation of the best and consideration of how in fact the ideal can be attained. Since his theory is not developed in synthetic detail-the reason being the undefined nature of the fundamental relation "better than"- the application of the theory cannot have the necessary nature of method that a fully developed formal theory would have. Mitchell's thus is a formal theory in ova. It follows with full methodological clarity the axiomatic course of an efficient axiological theory, and it thus arrives at insights beyond any other theory discussed so far, but its axiom is not rich and flexible enough to span the whole reach that a complete axiology must cover.

The same relative advantages and shortcomings appear in other theories based on Brogan's relation of "better than." For H. Timur, ${ }^{123}$ whose melioristic axiology is much less formal than Mitchell's, the fundamental fact of objective value is that we can arrange all things of experience in a scale of excellence. Any experience is regarded by us as either better or worse, higher or lower, than some other. The error we commit when investigating the nature of objective value is that we try to go beyond this fundamental fact. We either look for a common ethical quality, as we look for a common physical quality in a class of physical objects, or we idealize a common desire. However, the idea of one thing's being superior to another cannot be analyzed any further; it is one of our ultimate modes of thought. Just as we are unable to discern goodness as a unique quality in value situations, we are unable to discern evilness, which then also must be a unique quality. Yet, on the basis of betterness we may define the common terms "good" and "evil," "value" and "disvalue." "Good," though positive in form, is comparative in meaning. The only difference between "good" and "better" is that in "good" the idea of relative excellence is implicit and in "better" it is explicit. The essential nature of goodness or value is the fact that a thing occupies a place in the upper part of the scale of excellence; 
the essential nature of evil or disvalue is the fact that a thing occupies a place in the lower part. Good is one pole of the scale of excellence and evil the other. Good and evil, therefore have some of the characteristics of contradictory terms. The same aspect of the same thing cannot at the same time be good and evil. Also, if a thing is not bad, it is in some degree good, and vice versa. Betterness is the common concept underlying both good and evil.

Since the relations between these terms are not determined by Timur with anything like Mitchell's or even Brogan's precision, these concepts cannot be applied with precision to moral reality; thus, Timur's perceptive valuational judgments do not profit to any large degree from his conceptual framework. The concepts of superiority-inferiority that pervade "every scale of value from top to bottom" 124 are analytic material concepts; the scales therefore are metaphorical rather than real scales, as they could be if superiority-inferiority were formal synthetic concepts. Even though Timur says important and suggestive things about the value scale, as when he takes Brogan to task for disregarding the gap between "better" and "worse"; the smallest good is infinitely removed from the smallest evil, the enjoyment of the smallest pleasure infinitely removed from the suffering of the smallest pain. So I feel that there is more to the scale than even Timur says: a precision is possible of which his description is only an intimation-just as Plato felt that there must be precise numerical units to logical division, and that these measures would be of fundamental importance for the notion of value. ${ }^{125}$ The axiological quest must not rest until precise logical relations have been found to determine the betterness of one thing over another, until betterness, or goodness, has been defined synthetically.

Other theorists have attempted to define betterness on the basis of goodness. Felix S. Cohen defines "better than" by reference to an undefined notion of "good." 26

\section{1. $A$ is better than $B$ means There is an event, $C$, such that the logical} conjunction of $C$ and $A$ is good, while the conjunction of $C$ and $B$ is not good.

The third event, $C$, acts, so to speak, as a standard for judging the relative merit of $A$ and $B$.

For example, keeping a hundred children from spinal meningitis $(A)$ is better than keeping a thousand dogs from vivisection $(B)$ if, and only if, there is some third event, say sickness of fifty children $(C)$, which taken with the preserved health of the hundred children (A.C) constitutes a series of events that is on the whole good, but taken with the rescue of the thousand dogs $(B . C)$ does not form a good whole. Or, to take an example where it may be easier to focus attention on intrinsic values, the enjoyment of Beethoven's Seventh Symphony on a given evening of the reader's life $(A)$ is better than the conversation of a friend $(B)$, if there is some third event $(C)$ such as the waste of an hour in traveling which, taken with the concert $(A . C)$, is good, with the conversation (B.C), not good. ${ }^{127}$ 
In all, there are five cases in which definition can be applied:

(A) $A$ is good and $B$ is bad. In this case we can always conceive an indifferent event, the conjunction of which with $A$ would produce a good, though its conjunction with $B$ would not produce a good.

(B) $A$ is good and $B$ is good. In this case, if $A$ is better than $B$, there will be some bad event which will in conjunction with $B$ constitute a total that is not good (that is, either bad or indifferent), although it is not bad enough to make the conjunction $A . C$ not good.

(C) $A$ is bad and $B$ is bad. In this case, if $A$ is better than $B$, there will be a good event, $C$, sufficient to make $A$. $C$ good, yet not adequate to make $B . C$ good.

(D) $A$ is good and $B$ is indifferent. Here we may add a third independent event either indifferent or slightly evil, so that $A . C$ will remain good, while $B . C$ is indifferent or bad.

(E) $A$ is indifferent and $B$ is bad. Here a third event may conceived good enough to make $A$. $C$ good, while $B$. $C$ remains bad or moves up to the level of indifference.

To understand these five applications we need the definition of "worse," "indifferent," and "bad."

2. $A$ is worse than $B=B$ is better than $A$.

3. $A$ is indifferent $=$ If any event is good, the conjunction of that event with $A$ is good and, vice versa, if the conjunction of any event with $A$ is good then the event is good.

4. $A$ is bad $=$ Every indifferent event is better than $A$.

To these definitions Cohen adds the definition of "best" and "worst" in a given class:

5. $A$ is best in a given class $=A$ is a member of the class and is better than any other member of the class.

6. $A$ is worst in a given class $=A$ is a member of the class and any other member of the class is better than $A$.

As long as the fundamental term of this structure, "good," is undefined, the structure is not formal but empty. If I do not know what "good" means, and the formal definition has no material content, the formal system is materially empty; it is no true synthetic system. Although it has systematic import it lacks empirical import. Its axiom is not based on phenomenal insight into the subject. The empty formalism of the system appears in Cohen's own comparison of his six axiological definitions with six corresponding definitions in mathematics. If "good" corresponds to "positive number," " $A$, , " $B$," " $C$," mean numbers, and " $A . B$ " the algebraic sum of $A$ and $B$; the corresponding algebraic definitions are: 1. $A$ is greater than $B ; 2 . A$ is less than $B ; 3 . A$ is zero; $4 . A$ is a negative number; $5 . A$ is the greatest number in class $K$; and $6 . A$ is the least number in class $K .^{128}$ 
As is seen, Cohen's definitions of value relations are patterned after those of number relations. But, and this brings out the fundamental difference between the two sets of definitions, whereas the basis of the number relations, the concept "positive number," is exactly defined and forms the axiom of the mathematical system, the basis of the value relation, the concept "good," is undefined and cannot form an axiom in the axiological system. The comparison does bring out the fundamental similarity of the two systems: their structures are similar; an isomorphism exists between the series of number and that of value relations. In this purely formal sense, we are a step closer to a science of value. If the fundamental notion "good" were defined we would have a powerful axiological instrument, for we could use the properties of number for the understanding of value, the structure could have both systematic and empirical import, and the problem of a value science would be solved. As it is, Cohen gives us (and this is an important service) some of the formal characteristics of such a science.

1. The system as such does not presuppose either good or evil things, as little as the system of mathematics presupposes a world to be numbered. But if there are good or evil things, then the formulae of the system are applicable.

2. The language of the system is not common sense language but a technical language. What is called "better" in the system is different from what we think of as "better" in everyday affairs. Yet, the technical nature of "better" is the one that contains the meaning of the simpler everyday concepts. ${ }^{129}$

Although these actually are some of the properties of a science of value-as of any science - they are, up to this point, not properties of Cohen's own proposal. His system is not applicable to value reality, for goodness in the system is not defined. Hence, what his system calls "good" may be applied to what actually may be either good or bad. Herein, precisely, lies the lack of empirical import of the system. Secondly, connected with this, the technical definition for "better" does not really express the meaning of the everyday concept, again because it is based on no axiom of phenomenal relevance. According to Cohen's definition, if there is an event $C$ such that the logical conjunction of $C$ and $A$ is good, while the conjunction of $C$ and $B$ is not good, then $A$ is better than $B$. Thus, if drinking coffee with whipped cream is good and drinking coffee with TNT is bad, then whipped cream is better than TNT. This, of course, is nonsense. Whipped cream is better for coffee and TNT better for dynamiting rocks. The two are incomparable. Any definition of "better" must include the standard by which the things in question are to be compared, but $C$ does not supply it.

Formal axiology supplies it in the axiom derived from Moore's two different propositions that are both true of good: the standard is the intension of the thing's concept. A thing is good if it has its intensional properties and bad if it does not have them. Thus, of two things, one good because it fulfills its concept, say, a good automobile, and one bad because it does not fulfill it, say a bad automobile, the first is better than the second. The degree of possessing intensional properties determines the goodness and badness and hence the betterness of things. Their standard of 
comparison is their common concept. Unless things are in the same class they cannot be compared. We can, at best, say that of a good automobile and a bad suspender, the first is better as an automobile than the second as a suspender, or that the first is a better automobile than the second is a suspender. But we cannot say that one is simply "better" than the other. "Better" is no primitive value relation that can be understood without qualification. Cohen is right in founding it upon "good," even though such a foundation is empty as long as "good" is left undefined.

The synthetic axiom of formal axiology defines good in a materially relevant way. It is not merely formal but also material; this is what "synthetic" and "axiom" mean; it supplies the empirical import that is missing in Cohen. Yet, Cohen's extremely acute and systematic analysis proceeds to discuss the definition of "good," and in the process even considers the kind of definition I propose, only that this kind appears to him "something of a mystery.", 30

The "logical nature of goodness," he holds, is determined by the following three possibilities: the expression " $A$ is intrinsically good," (1) has no meaning, (2) has a constant meaning, (3) has a variable meaning. In the first view, the expression is neither a proposition nor a propositional function, but a meaningless assembly of words. This is the position of value nihilism, "a theory of ethics only in the sense that anarchism is a theory of politics or scepticism a theory of knowledge."131 It is the position of some of the more radical positivists, and Cohen rejects it. The second view is that of ethical absolutism. In this view " $A$ is intrinsically good" is a proposition that is either true or false. It means that " $A$ is intrinsically good" always has the same meaning, whatever this may be in one ethical theory or another. "Absolutism in this sense is the assumption of practically every ethical system that has been constructed."'132 Cohen neither accepts nor rejects this view, but he makes a significant mistake in explaining it. He believes that G. E. Moore is an absolutist because he regards good as a simple indefinable quality. Actually, what for Cohen is ethical absolutism for Moore is the naturalistic fallacy. The indefinability of Moore's "good" keeps "good" open for any kind of determination, as Moore himself makes clear, ${ }^{133}$ and this makes Moore a representative of ethical relativism in Cohen's third sense.

In this third sense, the expression " $A$ is intrinsically good" is not a proposition but a propositional function..$^{134}$ "Good" here is a variable that assumes values by interpretation, just as does " $x$ " in a mathematical expression. If "good" is undefined, as it is in Moore, it is of course, an unknown $x$, or better, $y$, and the expression " $A$ is good" is not a proposition but a propositional function. The naturalistic fallacy is for Moore precisely the substitution of a value for $y$, be it "pleasant," "self realizing," "following the will of God," or what not. If Cohen had seen this methodological, rather than material, meaning of Moore's doctrine, he would have come very close to my position. Moore stated the variable nature of "good." He failed to state the range of this variable- the range of substitutions that would make the propositional function a proposition and hence subject to truth or falsehood. Moore failed, in other words, to solve the problem of moral science; he only posed it; and this, his historical achievement, has never been clearly understood. Cohen calls the position in question 
that of ethical relativism and believes Moore to be against it. But the ethical relativism Moore is against is not what the expression " $A$ is intrinsically good" as a propositional function means. For, the run-of-the-mill ethical relativism only means that "good" can have many meanings, but not that "good" itself has the logical meaning of having many meanings, that is, that it is a variable in the logical sense. To construct relativism in this way is a contribution of Cohen that goes beyond the ordinary meaning of "ethical relativism" and adds to it its logical structure. But even Cohen himself was not clear about the nature of this logical addition. He built better than he knew. Cohen neither accepts nor rejects this position, but he recognizes its serious shortcoming, that of not determining the range of the variable "good."

Cohen's next step is to ask whether and how "good" can be defined, either in the proposition or the propositional function " $A$ is intrinsically good," either as a constant or a variable, either as a term of ethical absolutism or relativism. In both cases (the third case, ethical nihilism, having been rejected), there are two possibilities: either the expression " $A$ is intrinsically good" has or has no naturalistic meaning. The four possibilities of defining "good" then are:

(1) The expression " $A$ is intrinsically good" is identical with a natural proposition.

(2) It is not identical with any natural proposition.

(3) It is identical with a natural propositional function.

(4) It is not identical with a natural propositional function.

The first possibility, that " $A$ is intrinsically good" may mean, say, " $A$ is pleasant," is, according to Moore, a fallacy; but Cohen does not accept Moore's argument. It may well be, he says, that "good" is convenient mental short-hand for some natural term or complex of terms. "No persuasive reason has been produced to show that every attempt to define good analytically must be doomed to failure." 135 The only proof Moore could attempt for this position would be to show that every possible analysis of good is incorrect, and this he did not attempt to do. Thus, "We can only examine in detail the types of natural definition that can be advanced and endeavor to consider in each case whether the suggested definiens really means what good means." 136

Again, Cohen misunderstands the methodological nature of Moore's fallacy: to define "good" by any definite property is false because "good" is not a constant but a variable; the expression " $A$ is intrinsically good" is not, if we understand Moore correctly, a proposition but a propositional function. Yet, Cohen believes, it may be a proposition and it may be a natural one, so good may well have one naturalistic (or metaphysical) meaning. He thus accepts the first definitional possibility of "good."

The second such possibility is the one Cohen identifies with Moore's position. Good is some definite property, but it is not a naturalistic (or metaphysical) one. This position, says Cohen, presupposes an absolute dualism between the realm of nature and that of value. Although Cohen does not deny this possibility, he does not wish to accept it. Again, he misunderstands the "simplicity" and "indefinability" of the Moorean property "good." It is analytically indefinable and simple, but not syntheti- 
cally so. Although it is not a natural property it is yet a property such as number ${ }^{137}$ and hence may be defined as such. But number is a variable, and expressions such as $2+2=4$ consist of variables in so far as the class of couples and the class of quadruples may consist of sets that consist of any kind of individuals whatever. This was made clear by Bertrand Russell in the very year that Principia Ethica appeared, 1903. In that year, the solution of Moore's paradoxes of goodness appeared implicitly in Russell's Principles of Mathematics. Yet, the relevance of the one book for the other has never been recognized, in spite of Moore's own hint at the mathematical analogy. Since number is the class of classes similar to a given class, the range of values that the variable "number" can take are classes similar to a given class, or sets in one-to-one correspondence to a given set. Similarly, since axiological value is the class of classes-of-properties (intensional sets) similar to a given class of properties (intensional set), the logical value the variable "axiological value" can take are intensional sets similar to a given intensional set. " $A$ is good," thus, is not a proposition but a propositional function.

This means that the definitional possibility in question must be either (3) or (4). According to the third possibility, " $A$ is intrinsically good" is identical with some natural propositional function; "good" would have to be interpreted as a set of natural properties. This, according to Cohen, would be the case if the expression were defined by some expression such as "I approve of $A$." In this case, the expression "is neither true nor false in value, but becomes true in some cases and false in others as the $I$ is given a definite reference." 138 "I" in other words, is itself a variable. The approval depends on the ethical standard that the individual chooses. Depending on the standard chosen, "good" will vary and hence the goodness of $A$. Cohen inclines to accept this view and to examine definitions of this kind piecemeal in the light of our experience.

Actually, we have here a logical determination of all possible naturalistic standards of value. Such standards may be determined not only by individuals but also by societies, situations, contexts, and the like. We have here a logical determination of the various forms of contextualism. If good is what is regarded as approved in a context, then forms such as "I," "you," and others which are "context-dependent," appear as values of the naturalistic propositional function " $A$ is intrinsically good" or " $A$ is good." But again, the range of this variable is not determined - except as "naturalistic" - and the propositional function has no meaning beyond that, that is, beyond saying that ethical standards are those chosen by individuals, societies, contexts, and so on.

We are left, then, with the last definitional possibility, that " $A$ is intrinsically good" is a propositional function but not identical with any naturalistic one. In other words, "good" is a variable but its range of values does not consist of natural terms. This possibility seems to Cohen improbable because incomprehensible. What could be these non-naturalistic terms? It would mean that 
although in different references or connotations the value judgment means different things, what is common to these judgments is not something which can be expressed in terms of psychology or any other positive science. There are no conceivable arguments for such a position, since the arguments for relativism are all based upon the ground that good is definable in natural terms, while the arguments for the indefinability of good are all based upon the belief that goodness is a constant quality which natural terms are unable to approximate. What sort of indefinable constant element could produce relative value judgments through dependence upon a variable is something of a mystery. We may conclude that this fourth alternative theory of the nature of the value predicate is, on the whole, an improbable one. ${ }^{139}$

Here we have a good statement of the dilemma of ethics. What relativism (or naturalism) has proposed is definable but not good; what absolutism (or non-naturalism) has proposed as good is not definable. How can the indefinable propose something that is natural (and relative)? The solution is, of course, that the "indefinable" refers to a universe of naturalistic (relative) events. The "mystery" is solved, as are Moore's paradoxes, by the formal definition of good in terms of a logical relation-that of fulfillment of conceptual intension, by analogy to the formal definition of number in terms of a logical relation, that of the correspondence of classes. The range of the variable "good," in other words, is the non-naturalistic range of logical intensions - and it is natural in that these intensions consist of natural properties. "Good" is a variable and hence indefinable as a constant; it is non-natural. Yet, on a different level, the level below the non-natural, it is natural. This is the solution not only of the range of the variable "good" but also of Moore's paradoxes and the axiological suggestion of "polyguity," "homonymity," and such. It is, in a word, the determination of the fundamental axiological relation.

Thus we have come full circle. With Cohen the problem of the definition of good has approached very closely to my own solution. Only those axiological thinkers remain who have directly related the fullness of logical intension to the nature of goodness; then my program of showing the transition from moral philosophy to moral science is completed.

There are really only two such thinkers, Daniel Christoff and J. O. Urmson. In both the relation between logical intension and value, although it is definitely this relation, suffers characteristic distortion; and the fundamental axiological relation is seen in a peculiarly distorting mirror.

Daniel Christoff ${ }^{140}$ uses the idea of fullness of logical being as the "foundation of a logic values" in the following acute way: every judgment of fact transcends its content and is accompanied by a value judgment since it implies the choice of the frame of reference or the order within which its truth or falsity is to be determined. I have elsewhere developed a naturalistic approach to the same idea. ${ }^{141}$ Value, for Christoff, may be defined as that which a concept lacks in order for the judgment, of which it is the subject, to be recognized as objectively true. The structure of 
judgment itself contains a representational or informative and a valuational aspect. In the proposition, "Socrates is a man," the term "man" can be used extensionally as class and intensionally as value. In the second sense, the proposition means that Socrates fulfills the meaning of "man." The informative aspect may be expressed by a general or a singular concept. In the first case, the concept, being itself an infinite possibility of judgments and of relations, is itself a relation, expressed in its definition, which delimits the concept to a certain nature of judgments. Within these limits, every concept has a double aperture, extension and intension, which represent, so to speak, the inferiority of a concept. ${ }^{142}$ The value of the concept is the greater-its truth is the more wanting, that is, desired or desirable - as the concept lacks order, or the order in which it is to be integrated is more complex. In the second case, that of a singular concept-" "this window," "this tree"- the concept is extremely uncertain if not actually undetermined, for what corresponds to it is not an order at all but one single object. Here the value of truth is at its highest because most wanting (although what the judgment affirms is reality itself, that of the object). Thus, in general, the value of a concept resides in its uncertainty or indeterminateness. As long as the concept is a general one and part of a well-defined system of other concepts, its value is almost zero; it borrows its value from the order to which it belongs. The value of that order is the greater as that order alone assures the truth of all the concepts that constitute it. In my terminology, a synthetic concept has almost no value, but a synthetic system has a very high value. The value of a concept is at its highest when it is a singular concept belonging to no order, or when it is a summum genus, belonging to the most abstract (analytic) order. The uncertainty of these matrices gives a high price to certain unique concepts and the highest ideas - among them the principle of deduction ${ }^{143}$ - but a lesser price to concepts that can be deduced one from the other within firm matrices. Some concepts express the idea of perfection or plenitude, such as "goodness," "generosity," and "grace." With these high analytic concepts our capacity of representation does not suffice to give them content. We can only distinguish degrees of adequacy with which we can intellectually approximate the plenitudes they express. Some positivists, from the analytic point of view, would say, "We can only distinguish degrees of adequacy with which we can intellectually approach the platitudes they express." The insignificance of our intellectual powers causes a feeling of value born from want. Value, then, is nothing but the positive idea of a lack; it signifies a certain nothingness, a nothingness not of being but of logical determination. In short, the value of a concept resides in the lack of matrix of which it is a part and is the higher the less ordered is this matrix, for such disorder accentuates the lack. (Compare this notion of "wanting" with that of F. E. Sparshott in Chapter Five.)

This is a most curious but most ingenious view, the core of which is an ontological interpretation of what I call the logical definition of "ought,"144 yet it leads to logical conclusions. According to it, a synthetic concept has the least value, an analytic concept has more value, and a singular concept has the highest value. This theory expresses from a negative point of departure - value is want of order - the 
exact hierarchy of value that formal axiology derives from a positive point of departure-value is fullness of order.

Since synthetic concepts have, by definition, fewer intensional properties than analytic concepts, and analytic concepts fewer such properties than singular concepts, less fulfillment is possible with synthetic concepts than with analytic concepts, and less with analytic concepts than with singular concepts. Since, in formal axiology, fulfillment of a concept defines value, synthetic conceps have less value than analytic concepts, and analytic concepts less value than singular concepts. In other words, synthetic concepts have the least value, analytic concepts have more value, and singular concepts the highest value. ·

As Christoff changes the plenitude of logical being into its opposite and makes lack of such being the basis of value, so J. O. Urmson ${ }^{145}$ changes the universality of logical being into particularity-in accordance with the Oxford School. Through this reinterpretation, he makes it the basis of valuation and suitable, among other things, to approach a solution of Ossowska's dilemma. Instead of speaking of the qualities that make up a thing, he speaks of "criteria," meaning by this the thing's qualities insofar as they are used for valuing the thing - in the terminology of other writers discussed above, the "good-making" qualities used qua good-making. Through this change of terminology he changes the logical context into the valuative one: instead of definitions of concepts or things he speaks of "definitions of qualities" and "standards of grading," and instead of the value property he speaks of "grading labels." "Good" for him is a "grading label applicable in many different contexts, but with different criteria for employment in each." ${ }^{146}$ The relation between the criteria for the goodness and the goodness of the thing, the fundamental axiological relation, is for him neither analytic nor synthetic. It is not analytic for if the grading label "good" were in each case

merely shorthand for the sum of the criteria (naturalism) we should have the absurd situation that "good" was a homonym with as many punning meanings as the situations it applied to; it would not significantly be used of a theatrical performance in the sense in which it is used of an apple. ${ }^{147}$

This, Urmson believes, "constitutes a most graphic refutation of naturalism." For other writers such as Paul Edwards, this very "polyguity" served as basis for their naturalism. But, Urmson continues,

to regard the relation between 'good' and the criteria for a good apple as synthetic is equally absurd. If someone were to admit that an apple was of two inch diameter, regularly shaped, of pleasing taste, high vitamin content and pest-free, nor claimed that it lacked some other essential characteristic but none the less denied that is was a good apple, it would not merely be empirically surprising; it would involve a breakdown in communication. ${ }^{148}$ 
What, then, is the relation between good-making criteria and "good"? The criteria are different in each situation, yet the goodness or badness is objectively decidable. It is not merely a matter of subjective likings; rather, it is a matter of the acceptance of grading criteria. If a stable majority of people prefer, say, cheese with the characteristics $A, B, C$, then these characteristics are the ones accepted, even by the minority, for grading cheese, and cheese that has them is "good."149

Even moral goodness can be determined in this way. Although it seems that to call someone a good man is logically different from calling him a good cricketer, there is no need for expecting a logical difference since the moral grade is not different in kind from the social. (See R. M. Hare's argument on this subject in Chapter Five above.) It is merely the one that refers to the totality rather than to sections of our life. Social intercourse and manners are the nearest approach to morals; indeed, they form an intermediate stage between individual function and character. This assertion is denied by Karl Britton, ${ }^{150}$ who holds that goodness in kind is logically different from moral goodness which, whatever it is, is not in kind.

Formal axiology makes clear what this logical difference is by defining both the logical nature of goodness in kind, such as social goodness, and of goodness that is not in kind, such as moral goodness. There is a definite logical difference between the goodness of a good cricketer and that of a good person, and this difference appears in Urmson's own account. For if moral goodness does refer to the totality of our life and social goodness to sections of it, then moral goodness is of a higher logical type than social goodness, by the principle we so often encountered, that a totality is on a higher logical level than the elements of which it consists. To see this clearly and systematically we must now turn to formal axiology.

\section{The Formal Nature of Value: Axiological Science}

Our survey has shown the infinite variety by which value philosophers have presented the fundamental axiological relation between fact and value, but without seeing its logical core discovered by G. E. Moore: it is a relation between descriptive and non-descriptive properties. This I supplement by the simple observation that value is the degree in which a thing fulfills its conceptual intension. It is difficult for the human mind to see the obvious, and nothing is more obvious than that the value of a thing supposed to be $C$ is the degree of its being $C$. At the same time, nothing is more fundamental, for this view makes available the whole of logic as an instrument for the comprehension of valuation. It identifies two things never before explicitly combined, logical concept and axiological norm. The concept of the thing is its norm; hence, the nature of norms depends on the nature of concepts. Since the nature of concepts is well known and logically structured, so is that of norms.

This procedure is the same as all scientific procedure. Today, nothing is more obvious than that a motion of ten miles an hour means a velocity of ten miles an hour; but that the relation between the ten miles in space and the hour in time was the simple one of arithmetical division was a transcendent insight. It brought on a revo- 
lution, and indeed the deepest-going revolution humankind has experienced, that from natural philosophy to natural science. This simple relation had to be lifted out of a matrix of theology, cosmology, ontology, psychology, and physiology in which it was embedded so deeply as to be all but unrecognizable - like a very fine nerve embedded in a fatty tissue to which, yet, it gives life. Time and again philosophers, such as Occam, had approached the simple truth, but it was Galileo who saw not only the simplicity of the relation but also its transcendent significance.

Similarly, I lift the simple relation between factual and value properties out of the theological, cosmological, ontological, psychological, physiological matrix in which it is embedded so deeply as to be all but unrecognizable — like the very fine nerve embedded in the fatty tissue of fact to which, yet, it gives life. My scalpel is the synthetic rather than analytic, the formal rather than material method, which revealed to us the axiological fallacies. With its help I dissected the tissue in the last three chapters of this book and am now ready to excise the nerve.

My approach has shown that Value has everything to do with value only when it has nothing to do with it. In other words, the very core of value is formal; and formal Value is as different from value (pleasure, choice, and so on) as the symbols " $\mathrm{E}=\mathrm{mc}^{2}$ " are from a nuclear bomb. Yet, this formula is what makes the bomb tick, and the formula for Value - "the degree of intensional fulfillment"-is what makes all values tick. This we shall now investigate somewhat more closely.

The fundamental axiological relation appeared in many ways in value philosophy - phenomenologically, ontologically, teleologically, biologically, psychologically, sociologically, contextually, and so on; but all such appearances were more or less crude, fatty strings of tissue that concealed rather than revealed the value relation. Yet, off and on philosophers approached the nerve of the matter - which had already been exposed by G. E. Moore-with notions such as "homonymity," "polyguity," in comparisons between definition and valuation, good-making and value properties, and the like. While the relation appeared in two ways in philosophy-in Moore's paradox of the two different propositions that are both true of goodness and in the notions of polyguity and such-it also appeared in natural science in the distinction between primary and secondary properties. Secondary properties are both the natural and the value properties of things, but not the scientific. We have thus three approaches to the axiom of formal axiology - the Moorean "prolegomena" to the science of ethics (an approach, we might say, between philosophy and science), the scientific, and the philosophical. Let us first review again Moore's approach and my deduction of the value axiom from it.

Moore's paradox of "the two different propositions [that] are both true of goodness, namely, that: (1) it does depend only on the intrinsic nature of what possesses it...and (2) though this is so, it is yet not itself an intrinsic property"151 is solved in the way of all paradoxes - by showing the difference of the logical orders in question. The two propositions refer to two different logical levels: the negative proposition concerning what goodness is not to the thing itself, and the positive proposition concerning what goodness is to the concept of the thing. For if "good" 
is a property indicating that the intension of the thing is being fulfilled, then it is not a natural property of the thing itself, but it is a property of the concept of the thing, namely, its intension's being fulfilled by the thing. To Moore's "depends on" belongs as counterpart a "corresponds to." The value property of a thing depends on the natural properties, which, in a good thing, correspond to the properties contained in the thing's concept. This correspondence is what makes the thing good. Moore saw that the value property depends on the natural properties of the thing, but he did not see the condition of this dependence: the logical nature of these properties as giving rise to the value predicate, their correspondence to the conceptual properties of the thing. Value, as Moore rightly saw, is not a natural property; yet, it depends only on these natural properties (and this was my addition to the Moorean determination of the nature of goodness) in so far as the natural properties correspond to the properties contained in the concept of the thing. In other words, the goodness of a thing depends only on the properties that define the thing's concept. With this axiom the problems of value become problems of logic. The value predicate "good," in not being a property of the thing, but in being a property of the thing's concept, is defined in a way similar to the Frege-Russell definition of the number predicate, for example, "four."

Let us now review the scientific approach. It compares Galileo's attack on the problem of motion with an axiological attack on the problem of value. In both cases the problem is one of finding a standard of measurement. Galileo found the standard of measurement of motion by disregarding the secondary qualities of the phenomena and concentrating on their primary qualities, that is, quantities amenable to measurement - centimeters, grams, seconds - so that what was measured was not the sense phenomenon of ordinary life with its secondary properties but a construct consisting of primary properties. In value measurement what is to be measured is the ordinary sense object not only as possessing its secondary properties, but this very possession is what measures its value. Hence for value measurement the secondary properties must be used as primary properties. The question was to find the standard that is to the secondary properties as primary standards - of length, weight, and so on - are to primary properties. What contains the secondary properties as, say, the meter contains the centimeter? The answer is: the intension of a concept. The concept, then, serves as the standard for value measurement-the same result as the deduction from Moore.

The notion of conceptual value measurement leads to dimensions of such measurements, just as does the notion of natural measurement of primary properties. Since concepts have different complexity or "plenitude," different intensity of content, the measures which things can fulfill in order to be good (or can fail to fulfill in order to be bad) are different. Depending on whether concepts are synthetic (constructs), analytic (abstractions), or singular, the number of possible properties they can contain is respectively finite, denumerably infinite, or non-denumerably infinite. The fulfillment of these respective concepts results in, respectively, systemic, extrinsic, and intrinsic value, that is, different value dimensions. These dimensions 
form a hierarchy of values that not only confirms Mitchell's isomorphism of transfinite mathematics and valuation, but also Christoff's value scale (even though it is contrary to his assumptions) and gives a mathematical interpretation to Urmson's discussion. The notion of value measurement leads to a calculus of values that applies the formal system of value with precision to value reality.

The philosophical approach, finally, leads to the same result. It demonstrates the purely formal and non-naturalistic character of the theory. "Good" is, as writers from Aristotle to Paul Edwards and J. O. Urmson have observed, an expression applicable in many different contexts with a different set of criteria for its employment in each. This, as has not been observed, happens to be the exact description of the logical nature of a variable. "Good" is a variable, and its logical values are actually fulfilled intensions, or axiological values. "Good" is that variable the logical values of which are axiological values. Its variable nature is expressed in laws of value just as the variable nature of, say, gravitation is expressed in laws of nature. These laws are applied to value phenomena just as natural laws are applied to natural phenomena. Thus, it is a law of value that if $x$ is a member of a class $C$ and possesses all the properties of $C$, then $x$ is a good $C$. It is a specification (interpretation or application) of this law that the thing over there is an armchair, has all the properties of an armchair, and therefore is a good armchair. The variable "good" has an infinite range, which in scholastic axiology made it one of the transcendentals; this range is structured since the concept $C$ can have any of the three intensional complexitiesthe constructive, the abstractive, and the singular; so its fulfillments may be systemic, or extrinsic, or intrinsic values.

The concept "chair" is systemically fulfilled in a chair factory, extrinsically in ordinary life, intrinsically in a still life (for example, Vincent van Gogh's Self-Portrait of a Chair). The concept "God" is systemically fulfilled in theology, extrinsically in comparative religion, intrinsically in mystic experience. The concept "man" is systemically fulfilled in physiology, extrinsically in sociology, intrinsically in ethics. The various specifications of the variable in various modes of the concept and in various fields of reality give rise to the various value sciences. Ethics, for example, is the application of intrinsic valuation to human beings. Morally good persons are those who fulfill their own concepts of themselves, are what they are ("genuine," "honest," "sincere"), and do not pretend or play roles. Extrinsically - sociologically - good people do play roles, as do good cricket players or streetcar conductors.

The logic of intensional complexities and rules of application give structure to von Rintelen's Real-Wert and Wert-Idee and supplement Northrop's macroscopic account of the epistemic correlation by a microscopic account of it. At the same time, the theory follows Margenau's program of using the method but not the content of science. For this reason it is non-naturalistically formal: it applies the scientific method to a subject sui-generis - value. The difference between fact and value is not material but formal or methodological; any event or thing seen under the frame of reference of natural science and its logic is a fact, and seen under the frame of reference of axiological science and its logic is a value. 
No valuation is, as such, emotive. Rather, the theory defines the strict distinction between feeling and valuation of Nicolai Hartmann and locates, with Rickman, the emotive in the application, by defining value psychology as a specific form of valuation. Neither is valuation, as such, metaphysical or ontological. Rather, metaphysics, too, is defined as a specific kind of valuation, namely, as intrinsic valuation applied to concepts. The same is true of the "contextual" and "situational" uses and functions of value terms. These terms are formally defined in the theoretical pattern, and their concrete uses are determined by the rules of application. The imperative form is determined through the definition of "ought." Urmson's "grading labels" are the axiological quantifiers-for example, "good" as the universal positive such quantifier, expressing that the thing does have all its intensional properties. His "standards of grading" are concepts as standards of secondary properties, and his "criteria" the units of these standards, the intensional properties. In a similar way, other value characteristics given by value philosophy ought to reappear, in a consistent pattern, in value science.

In such a science, value characteristics and distinctions ought to appear that have never appeared in the philosophy of value, and such a science ought to be able to penetrate to the very core of value situations in a way no value philosophy can. Synthetic value reason ought to be both extensionally wider and intensionally deeper than analytic value reason. So far I have dealt with axiological reason extensively, examining the variety of value theories. I shall now examine axiological reason intensively, showing how it explains specific value situations, both analytically as value philosophy and synthetically as value science. 